\title{
Formulation, Casting, and Evaluation of Paraffin-Based Solid Fuels Containing Energetic and Novel Additives for Hybrid Rockets
}

\author{
Daniel B. Larson, ${ }^{1}$ John D. Desain, ${ }^{2}$ Eric Boyer, ${ }^{1}$ Trevor Wachs, ${ }^{1}$ Kenneth K. \\ Kuo, ${ }^{1}$ Russell Borduin, ${ }^{3}$ Joseph H. Koo, ${ }^{3}$ Brian B. Brady, ${ }^{2}$ Thomas J. Curtiss, ${ }^{2}$ and \\ George Story $^{4}$ \\ ${ }^{1}$ The Pennsylvania State University, University Park, PA 16802 USA \\ ${ }^{2}$ The Aerospace Corporation, El Segundo, CA 90245 USA \\ ${ }^{3}$ University of Texas - Austin, Austin, TX 78712 USA \\ ${ }^{4}$ NASA-Marshall Space Flight Center, Huntsville, AL 35811 USA
}

Primary Technical Area:

Secondary Technical Area:
14. Innovative Rocket Propulsion Techniques

10. Test Methods and Diagnostic Techniques in Chemical Propulsion and/or Combustion of Energetic Materials

One of the most important factors currently preventing the practical use of hybrid rockets as boosters is the limited thrust level that can be generated from a simple port design. This limitation can be addressed either through a complex port geometry (with associated mechanical strength and fuel utilization issues) or by increasing the mass-burning rate of the oxidizer/fuel combination. A promising method to improve the regression rate of solid fuels used in hybrid rockets is to use a fuel with a high regression rate such as low melting point paraffin wax; however, additional increases to the fuel regression rate are necessary to make the fuel a viable candidate to replace current launch propulsion systems. Addition of energetic and/or nano-sized combustible particles can also increase mass-burning rates of the solid fuels and increase the overall performance of the hybrid rocket motor system. ${ }^{1,2}$ Improving the mechanical properties of the paraffin wax is also important to produce more robust solid-fuel grains. This investigation studied the effect of various additives to paraffin wax burned with gaseous oxygen in a test rig called the Long-Grain Center-Perforated (LGCP) hybrid rocket motor. Shown in Figure 1, this labscale motor has been used for characterization of various oxidizer and fuel formulations. ${ }^{3}$

Several paraffin-based fuel grains with various energetic additives [e.g., lithium aluminum hydride $\left(\mathrm{LiAlH}_{4}\right)$ and cyclotrimethylenetrinitramine (RDX)] have been cast, and paraffin/ $\mathrm{LiAlH}_{4}$ fuel grains have been tested at representative oxidizer flux conditions. A major advantage of using $\mathrm{LiAlH}_{4}$ as an additive to paraffin is the decreased dependency of $\mathrm{I}_{\mathrm{sp}}$ on oxidizer-to-fuel ratio. However, previous testing showed that continued work is necessary to eliminate deposition of unburned/unreacted fuel in downstream sections of the hybrid rocket motor. ${ }^{4}$ Changes to the fuel matrix include higher melting point wax and smaller (ball-milled) $\mathrm{LiAlH}_{4}$ particles. With these changes, much more complete combustion was observed. Addition of $\mathrm{LiAlH}_{4}$ at $10 \%$ by weight was found to increase regression rates between $7-10 \%$ over baseline paraffin. Mass burning rates were also higher.

Another promising fuel formulation consideration is to incorporate a small percentage of RDX as an additive to paraffin. A novel casting technique was used by dissolving RDX in a solvent (dimethylformamide) chosen for its compatibility with both paraffin and RDX, and combining the solution with the melted paraffin. The solvent was then evaporated out of the mixture, leaving the re-crystallized RDX dispersed in the paraffin. At low percentages of RDX additive and with RDX particles surrounded by paraffin, the fuel grains can remain inert, maintaining safety of the solid fuel. It was found that although all the solvent was removed, the process as currently applied was not conducive to generating small RDX particles. Neither rapid boiling nor slow removal of the 
dimethylformamide produced particles of satisfactorily small size. Large particles were observed to settle in the melted paraffin wax, generating a non-homogeneous fuel grain structure.

One approach to improve mechanical properties of paraffin wax is with the addition of multi-walled carbon nanotubes (MWNT). For casting these solid-fuel grains, various percentages of MWNT were debulked via a sonication process similarly described in the literature ${ }^{5}$ and then added to the paraffin wax. The cost of MWNT is a small fraction of single-walled nanotubes. This is a scale-up advantage as future applications and projects will require low cost additives to maintain cost effectiveness. The fuel samples containing MWNT (up to $8 \%$ ) showed good distribution of MWNT in the paraffin matrix, but the MWNT were often agglomerated, indicating that a change to the sonication and mixing processes were required to achieve better uniformity and debundled MWNT. Fuel grains with MWNT fuel grains had slightly lower regression rate, likely due to the increased thermal conductivity to the fuel subsurface, reducing the surface temperature.

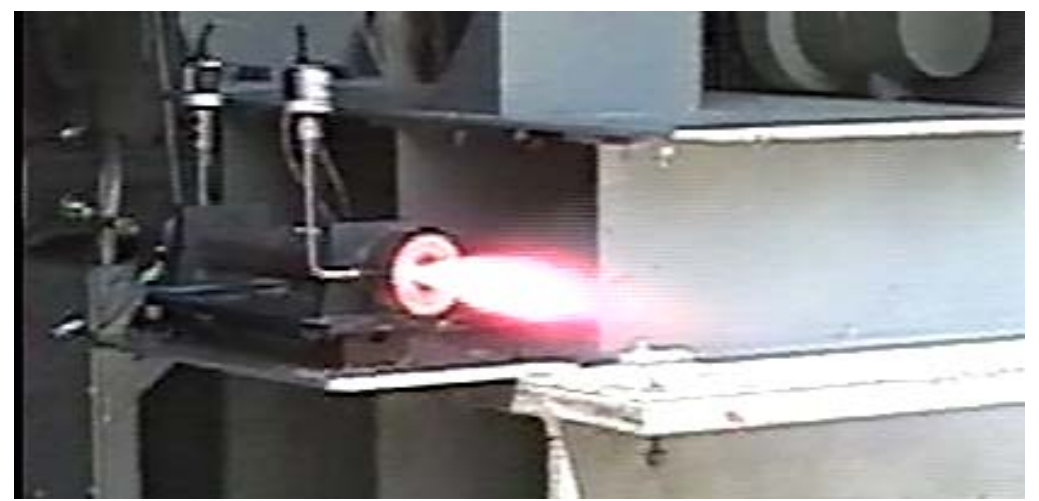

Figure 1. Photograph of LGCP hybrid rocket motor firing with a pure paraffin fuel grain manufactured by the Aerospace Corporation

\footnotetext{
${ }^{1}$ Kuo, K. K., Risha, G. A., Evans, B. J., and Boyer, E., "Potential Usage of Energetic Nano-Sized Powders for Combustion and Rocket Propulsion," Characterization and Properties of Energetic/Reactive Nanomaterials, Materials Research Society , ed. W. Wilson, et. al., Pittsburgh, PA, Invited Paper, December 2003.

${ }^{2}$ Risha, G. A., Boyer, E., Evans, E., and Kuo, K. K., "Characterization of Nano-Sized Particles for Propulsion Applications," Characterization and Properties of Energetic/Reactive Nanomaterials, Materials Research Society, ed. W. Wilson, et. al., Pittsburgh, PA, Invited Paper, December 2003.

${ }^{3}$ Risha, G., Boyer, E., Wehrman, R., and Kuo, K. K., "Performance Comparison of HTPBBased Solid Fuels Containing Nano-Sized Energetic Powder in a Cylindrical Hybrid Rocket Motor," AIAA-2002-3576, 38th AIAA/ASME/SAE/ASEE Joint Propulsion Conference and Exhibit, Indianapolis, Indiana, July 7-10, 2002.

${ }^{4}$ Larson, D. B., et al., "Characterization of the Performance of Paraffin/LiAlH4 Solid Fuels in a Hybrid Rocket System," AIAA 2011-5822, 47th AIAA/ASME/SAE/ASEE Joint Propulsion Conference and Exhibit, San Diego, CA, July 31 - August 3, 2011.

${ }^{5}$ Slobodian, P., Lengálová, A., Sáha, P., and Ŝlouf, M., "Poly(methyl methacrylate)/Multiwall Carbon Nanotubes Composites Prepared by Solvent Cast Technique: Composites Electrical Percolation Threshold," Journal of Reinforced Plastics and Composites, Vol. 26, No. 16, Sage Publications, 2007.
} 


\title{
FORMULATION, CASTING, AND EVALUATION OF PARAFFIN-BASED SOLID FUELS CONTAINING ENERGETIC AND NOVEL ADDITIVES FOR HYBRID ROCKETS
}

\author{
Daniel B. Larson, ${ }^{1}$ John D. Desain, ${ }^{2}$ Eric Boyer, ${ }^{1}$ Trevor Wachs, ${ }^{1}$ Kenneth K. Kuo, ${ }^{1}$ \\ Russell Borduin, ${ }^{3}$ Joseph H. Koo, ${ }^{3}$ Brian B. Brady, ${ }^{2}$ Thomas J. Curtiss, ${ }^{2}$ and George Story ${ }^{4}$ \\ ${ }^{1}$ The Pennsylvania State University, University Park, PA 16802 USA \\ ${ }^{2}$ The Aerospace Corporation, El Segundo, CA 90245 USA \\ ${ }^{3}$ University of Texas - Austin, Austin, TX 78712 USA \\ ${ }^{4}$ NASA-Marshall Space Flight Center, Huntsville, AL 35811 USA
}

\begin{abstract}
This investigation studied the inclusion of various additives to paraffin wax for use in a hybrid rocket motor. Some of the paraffin-based fuels were doped with various percentages of $\mathrm{LiAlH}_{4}$ (up to $10 \%$ ). Addition of $\mathrm{LiAlH}_{4}$ at $10 \%$ was found to increase regression rates between $7-10 \%$ over baseline paraffin through tests in a gaseous oxygen hybrid rocket motor. Mass burn rates for paraffin grains with $10 \% \mathrm{LiAlH}_{4}$ were also higher than those of the baseline paraffin. RDX was also cast into a paraffin sample via a novel casting process which involved dissolving RDX into dimethylformamide (DMF) solvent and then drawing a vacuum on the mixture of paraffin and RDX/DMF in order to evaporate out the DMF. It was found that although all DMF was removed, the process was not conducive to generating small RDX particles. The slow boiling generated an inhomogeneous mixture of paraffin and RDX. It is likely that superheating the DMF to cause rapid boiling would likely reduce $\mathrm{RDX}$ particle sizes. In addition to paraffin/ $\mathrm{LiAlH}_{4}$ grains, multi-walled carbon nanotubes (MWNT) were cast in paraffin for testing in a hybrid rocket motor, and assorted samples containing a range of MWNT percentages in paraffin were imaged using SEM. The fuel samples showed good distribution of MWNT in the paraffin matrix, but the MWNT were often agglomerated, indicating that a change to the sonication and mixing processes were required to achieve better uniformity and debundled MWNT. Fuel grains with MWNT fuel grains had slightly lower regression rate, likely due to the increased thermal conductivity to the fuel subsurface, reducing the burning surface temperature.
\end{abstract}

\section{INTRODUCTION}

There are many advantages to hybrid rockets over solid and liquid rocket propulsion systems. One key advantage is safety. In contrast to a solid propellant, where the fuel and oxidizer are integrally mixed, a hybrid motor consists of an inert fuel and a separated oxidizer. This simple design contrasts with the complexity of liquid rocket systems. With an inert fuel, shipping and storage costs for hybrid fuels are significantly reduced, lowering overall cost. Hybrid fuels can also present lower environmental hazards due to exclusion of ammonium perchlorate (AP), which is commonly used as an oxidizer in solid propellants. This reduces impact on groundwater and the environment. A hybrid can also be throttled and has the potential 
for stop and restart on demand. Although there are many benefits to using a hybrid rocket system, improved burning rates and mechanical strength would further raise the technology readiness level (TRL) of paraffin-fueled hybrid rockets. ${ }^{1}$ Paraffin wax-based solid fuels for use in hybrid rockets have shown regression rates which are far superior to conventional pyrolyzing fuels, with burn rates three to four times higher than HTPB. ${ }^{2,3}$ To further improve the mass burning rates of solid fuels, it is often useful to employ energetic and/or nano-sized particles. Hybrid rocket solid fuels with energetic or nano-sized particle additives have demonstrated significantly higher burning rates over baseline fuels. ${ }^{4,5}$

In an effort to improve the mass burn rates of hybrid rocket motors, the co-authors from the Aerospace Corporation have formulated and cast several solid-fuel grains containing lithium aluminum hydride $\left(\mathrm{LiAlH}_{4}\right.$ or $\left.\mathrm{LAH}\right)$. The $\mathrm{LiAlH}_{4}$ fuel grains have shown the ability to ignite with strong acids, demonstrating the potential for restart on demand with a simple ignition method. The reaction of the paraffin fuel $\left(\mathrm{C}_{32} \mathrm{H}_{66}\right)$ doped with $\mathrm{LiAlH}_{4}$ to strong acids (e.g., nitric acid) was found to be hypergolic. ${ }^{6,7}$ A key benefit of using $\mathrm{LiAlH}_{4}$ in paraffin wax are reduced dependency of specific impulse $\left(I_{s p}\right)$ on oxidizer-to-fuel ratio. The $\mathrm{LiAlH}_{4}$ addition allows for system operation through a wider range oxidizer-to-fuel ratio $(\mathrm{O} / \mathrm{F})$ while remaining close to peak $\mathrm{I}_{\text {sp. }}$ This benefit is shown in Fig. 1. Addition of $\mathrm{LiAlH}_{4}$ to paraffin also increased theoretical characteristic velocity. Previous tests on solid-fuel grains revealed that a change in to the fuel matrix (i.e., higher melting point fuel and smaller $\mathrm{LiAlH}_{4}$ particles) might help to reduce the amount of unburned fuel which was accumulating in downstream sections of the hybrid motor (up to $22 \%$ of mass lost). ${ }^{8}$ Smaller (ball-milled) $\mathrm{LiAlH}_{4}$ particles have been found to dehydrogenate more rapidly, the first step in the decomposition reaction of $\mathrm{LiAlH}_{4}{ }^{9}$

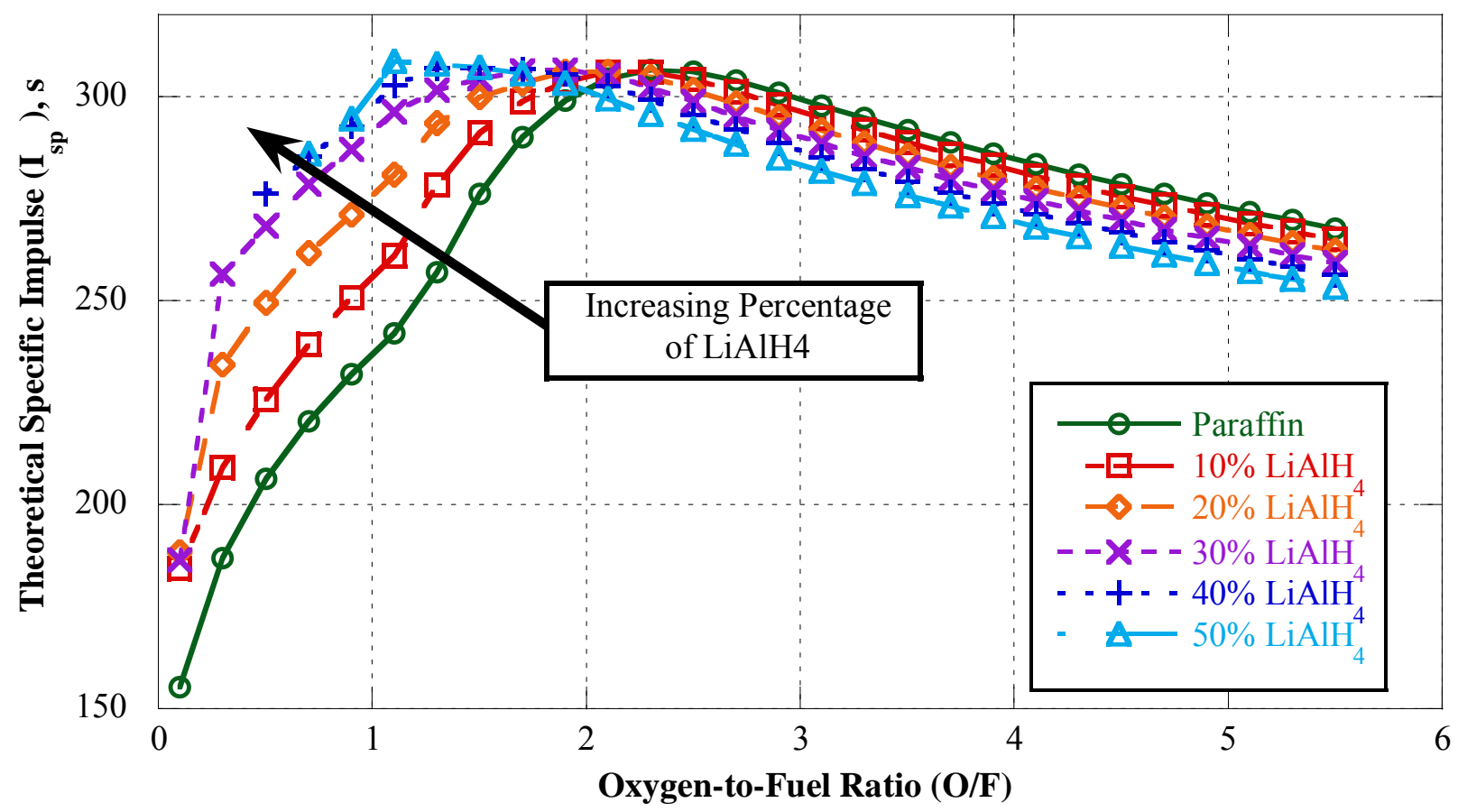

Figure 1. Thermochemical calculations of $I_{s p}$ for various percentages of $\mathrm{LiAlH}_{4}$ in paraffin wax (calculated for chamber pressure of 6.9 MPa with a nozzle expansion ratio of 10) 
Cyclotrimethylenetrinitramine $\left(\mathrm{C}_{3} \mathrm{H}_{6} \mathrm{~N}_{6} \mathrm{O}_{6}\right)$, commonly known as $\mathrm{RDX}$, is another additive with the potential to increase bulk density as well as improve the mass burning rates of paraffin. With a density of $1.82 \mathrm{~g} / \mathrm{cm}^{3}, \mathrm{RDX}$ is around twice the density of paraffin wax. ${ }^{10} \mathrm{In}$ addition to increasing the bulk density of the hybrid fuel, RDX may also increase the mass burn rates of the fuel, because it is an energetic material. RDX is a familiar ingredient in rocket and high-energy gun propellants. A novel casting technique of dissolving RDX in a solvent which is compatible with paraffin wax could produce well-dispersed particles of RDX embedded in a paraffin fuel matrix.

Inclusion of RDX in low percentages $(<15 \%)$ would keep the solid-fuel grain effectively inert. A DOT Class $1.4 \mathrm{C}$ rating was given to fuel-rich propellant formulations containing $60 \%$ AP in an HTPB/PPG binder for use in a hybrid rocket. ${ }^{11,12}$ Keeping the fuel grain relatively inert with a hazard classification below 1.3 is essential to maintaining the overall safety and operability advantages of the hybrid system. Thermal and stability behavior of RDX is well known and documented. ${ }^{9}$ RDX is soluble in various solvents such as acetone and dimethylformamide $\left(\mathrm{C}_{3} \mathrm{H}_{7} \mathrm{NO}\right)$, and the solubility data has been extensively documented. ${ }^{13}$ Once the RDX is dissolved in the solvent, the solvent can be boiled out of the melted paraffin. The boiling point of dimethylformamide (DMF) is high $\left(\sim 153{ }^{\circ} \mathrm{C}\right)$, but a vacuum can be drawn to lower the boiling point of the DMF to a value closer to the melting point of paraffin wax. ${ }^{14} \mathrm{In}$ this study, DMF was selected due to its high solubility of RDX with boiling point higher than the casting temperature of paraffin wax at atmospheric pressure and a boiling point below the paraffin casting temperature at sub-atmospheric pressures.

Along with increasing bulk density and regression rate, the mechanical properties of paraffin can be improved to provide more robust solid-fuel grains. Mechanical properties of paraffin-based solid fuel have been tested and published. ${ }^{15}$ The inclusion of multi-walled carbon nanotubes (MWNT) has the potential to improve mechanical properties and change the burn rate of paraffin wax. Prior to this study, MWNT have been added to paraffin wax and tested for thermal performance. These samples showed an increase in thermal conductivity as MWNT additive amount increased. ${ }^{16}$ Mixing procedures for distributing multi-walled carbon nanotubes in polymers as well as a phenolic resin for ablative applications have also been documented in the literature. ${ }^{17,18}$ MWNT are much lower cost compared to single-walled nanotubes. Due to the mechanical strength advantageous and low cost, MWNT were selected as an additive to paraffin wax to determine mechanical property benefits and changes in regression rate.

\section{METHOD OF APPROACH}

Work presented in this paper occurred in several phases. The Aerospace Corporation ball milled $\mathrm{LiAlH}_{4}$ and cast paraffin-based fuel grains with various percentages of $\mathrm{LiAlH}_{4}$. Solid-fuel grains were also cast at the High Pressure Combustion Lab (HPCL) at the Pennsylvania State University (PSU). Solid-fuel grain samples which were processed at the HPCL included RDX and MWNT additives in paraffin. The paraffin wax with MWNT samples were sent to the Center for Nano and Molecular Science and Technology at University of Texas-Austin for TGA and SEM analysis. Along with these small ( $\sim 50$ gram) samples of solid fuel for thermal analysis, hybrid rocket fuel grains were also manufactured for test firings. All types of solid-fuel grains produced either at the Aerospace Corporation or at PSU were tested in a hybrid rocket system at PSU. 


\section{$\mathrm{LiAlH}_{4}$ Casting}

In order to reduce $\mathrm{LiAlH}_{4}$ particle size, the coauthors from the Aerospace Corporation used a ball milling technique. Because $\mathrm{LiAlH}_{4}$ is reactive with water, it must been kept in a nitrogen environment as much as possible. $\mathrm{LiAlH}_{4}$ particles were ball milled for various amounts of time and examined using SEM techniques. Particles milled for 300 hours were cast into paraffin wax with a melting point between 70 and $80^{\circ} \mathrm{C}$. This was performed by melting the wax and mixing the additives before pouring into a paper phenolic tube held inside an aluminum mold. The paper phenolic tube, which serves as the hybrid rocket motor solid-fuel cartridge, has an outer diameter of 1.5 inches $(3.81 \mathrm{~cm})$, an inner diameter of 1.25 inches $(3.175 \mathrm{~cm})$, and was cut to 16 -inch $(40.64-\mathrm{cm})$ lengths to fit inside the aluminum mold. Once wax was poured into the mold, it was spun on a lathe to bond the solid fuel to the case wall, because the wax shrinks during cooling. These steps were repeated for multiple pours to fill the fuel grain cartridge. After each grain had solidified, a center port between 0.35 and 0.51 inches $(.889$ and $1.295 \mathrm{~cm})$ was cut, and the grain was cut to lengths of 4,5 , and 5.5 inches $(10.16,12.7$, and $13.97 \mathrm{~cm})$ in order to maintain desirable combustion $\mathrm{O} / \mathrm{F}$ ratios at the three different oxidizer flux levels tested.

\section{RDX Casting}

Before casting full-size fuel grains for use in an HPCL hybrid rocket motor, 50 gram samples consisting of $4 \mathrm{wt} \%$ of RDX and $96 \mathrm{wt} \%$ of paraffin were generated. Wetted, Class I, Type II military grade RDX was measured and baked at low temperature in order to dry out the RDX powder. The RDX powder was then weighed again, and dissolved in approximately $15 \mathrm{~mL}$ of dimethylformamide. Once dissolved, the DMF/RDX solution could safely be transferred to the casting chamber, where paraffin wax had been melted and held at around $100{ }^{\circ} \mathrm{C}$. The heating and mixing setup is shown in Fig. 2. It should be noted that all mixer clearances were checked to avoid contact with the mixing bowl and equipment was grounded in accordance with DoD standards. With the mixer turned on, the DMF/RDX solution was poured into the melted paraffin. The environmental chamber door was then closed, and a camera with a live feed was placed near the window, so that the casting process could be monitored remotely.

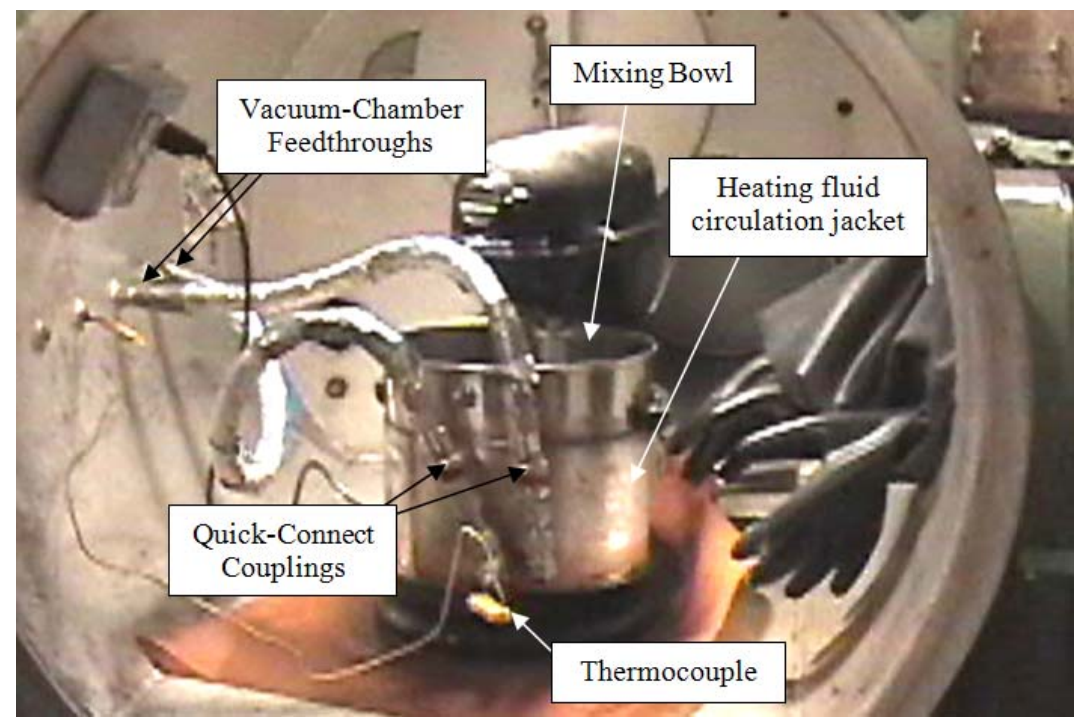

Figure 2. Solid fuel casting setup in vacuum chamber 
The chamber was then pumped down to approximately 4 psia $(27.6 \mathrm{kPa})$, where the boiling point of the DMF is around $110^{\circ} \mathrm{C}$. The paraffin temperature was raised to above this value, so that the DMF could boil out slowly, allowing RDX to nucleate out of the supersaturated DMF/RDX solution. After approximately 1.5 hours of continuous mixing, a vacuum was slowly drawn down to $\sim 1$ psia $(6.9 \mathrm{kPa})$ to check for bubbling from any remaining DMF. When there was no boiling of DMF, this indicated that no DMF remained in the mixture. The chamber was then pressurized, heating equipment was turned off, and mixing was stopped. Photographs of the liquid paraffin mixture with suspended RDX particles were taken before the paraffin cooled, to check for the dispersion status of RDX particles.

\section{MWNT Casting}

Casting of MWNT occurred in several steps. In order to evenly disperse the MWNT in paraffin and take advantage of their small size, the MWNT must be debulked. This is typically done by sonicating the MWNT in a solvent and then removing the solvent from the final material. In this study, the MWNT were sonicated in toluene. The typical ratio of MWNT to toluene was between 1 and 2 grams per $100 \mathrm{~mL}$ of toluene. The sonication process was limited to approximately 20 minutes, as toluene has been observed to break down if sonicated intensely or for long periods of time. ${ }^{19}$ Because toluene's boiling point is around $110{ }^{\circ} \mathrm{C}$, the paraffin can be heated slowly until it is above toluene's boiling point and held at that temperature until the toluene is fully removed.

After sonicating the toluene/MWNT mixture and adding it to paraffin held at around 100 ${ }^{\circ} \mathrm{C}$, the environmental chamber door was closed, with a vent line to atmosphere. Due to toluene's flammability in air, the environmental chamber was constantly purged with nitrogen during the mixing process until the toluene was removed. A fan was also used on the interior of the environmental chamber to promote circulation of the dense toluene vapors. Small scale batches of 50 grams were generated with various MWNT additive amounts ranging from 0 to $8 \%$ MWNT. These small scale samples were sent to the Center for Nano and Molecular Science and Technology at University of Texas-Austin for DSC, TGA, and SEM testing.

A fuel grain for testing in a hybrid rocket motor was also generated. The formulation for this grain was $4 \mathrm{wt} \%$ MWNT in paraffin wax. Instead of using an aluminum mold to seal the paraffin inside the phenolic fuel cartridge, PSU's casting process used end caps on the phenolic fuel cartridge. The grain was spun on a lathe at approximately $400 \mathrm{rpm}$ and then reheated in an oven to soften the wax before the next pour. This was performed to generate better bonding between poured layers and good adhesion of the fuel to the case wall. The grains were then cut to 4.5-inch (11.43-cm) lengths.

\section{Hybrid Rocket Motor Test Setup}

The hybrid rocket motor used to evaluate the solid-fuel grains in this study is called the Long Grain Center Perforated (LGCP) hybrid rocket motor. It allows for fuel grains with lengths up to 16 inches $(40.64 \mathrm{~cm})$ and has an inner diameter of 1.5 inches $(3.81 \mathrm{~cm}) .{ }^{5}$ Using graphite inserts as volume-filling spacers, fuel lengths can be varied significantly to control fuel burning surface area. The LGCP system is shown in Fig. 4. In these experiments, desired pressures were typically between 200 and 350 psia (1.38 MPa and 2.41 MPa), depending on nozzle size. The small size of the LGCP and fast turnaround times during testing make it an ideal motor for 
testing new fuel formulations, while consuming a minimal amount of fuel. The LGCP ran with gaseous oxygen and with a nitrogen purge for this test matrix, but the LGCP can accommodate other oxidizers such as nitrous oxide.

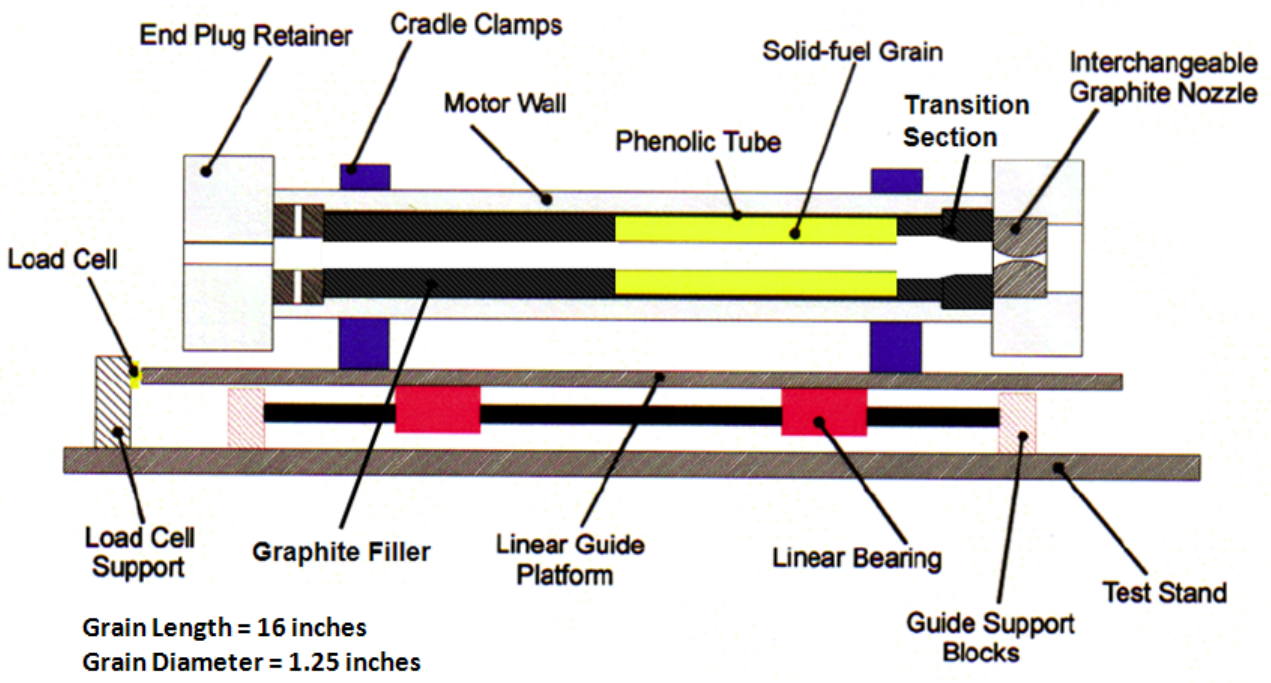

Figure 4. Schematic diagram of long grain center perforated (LGCP) hybrid rocket motor setup

The results from the LGCP motor firings are best for comparing different formulations of solid fuel because of the relatively thin fuel web and resulting short burn duration for highregression rate fuel formulations. Equations (1) and (2) were used in developing plots of regression rate versus oxidizer mass flux. ${ }^{20} \mathrm{D}_{\mathrm{i}}$ and $\mathrm{D}_{\mathrm{f}}$ are initial and final fuel grain port diameters respectively, and $t_{b}$ is the burn time. Final port diameter $\left(D_{f}\right)$ is often found by measuring in several places at the fore and aft end of the fuel grain after firing, but in the case of this study Eq. (3) is used. This relies on accurate measurements of grain mass and fuel density rather than center port diameters measured along the length of the post-fired fuel grain. In Eq. (3), $\mathrm{M}_{\mathrm{i}}$ and $\mathrm{M}_{\mathrm{f}}$ are the initial and final mass of the solid fuel, respectively.

$$
\begin{aligned}
\overline{\dot{r}} & \cong \frac{D_{f}-D_{i}}{2 t_{b}} \\
\bar{G}_{\mathrm{ox}} & =\frac{16 \dot{m}_{\mathrm{ox}}}{\pi\left(\mathrm{D}_{\mathrm{f}}+\mathrm{D}_{\mathrm{i}}\right)^{2}} \\
\mathrm{D}_{\mathrm{f}} & =\sqrt{\mathrm{D}_{\mathrm{i}}^{2}+\frac{4\left(\mathrm{M}_{\mathrm{i}}-\mathrm{M}_{\mathrm{f}}\right)}{\pi \mathrm{L} \rho_{\text {fuel }}}}
\end{aligned}
$$




\section{RESULTS AND DISCUSSION}

\section{$\mathrm{LiAlH}_{4}$ Casting Results}

The $\mathrm{LiAlH}_{4}$ ball milling process successfully reduced the particle sizes. As shown in Fig. 5, SEM images of the $\mathrm{LiAlH}_{4}$ particles reveal that after 300 hours, the particles are generally submicron size, with many particles less than $100 \mathrm{~nm}$. However, many of the particles have an alumina layer which would delay the decomposition of the particles during combustion. ${ }^{21}$ With these smaller particles, the $\mathrm{LiAlH}_{4}$ was successfully mixed into a high melting point (70 to 80 ${ }^{\circ} \mathrm{C}$ ) paraffin wax and cast in phenolic cartridges for testing in the LGCP hybrid rocket motor. Upon cutting the solid fuel grains prior to testing, the fuel grains appeared homogeneous with few voids or defects. Although center port diameter varied, the grains were deemed usable for hybrid rocket motor tests after measuring average mass and center port diameter.

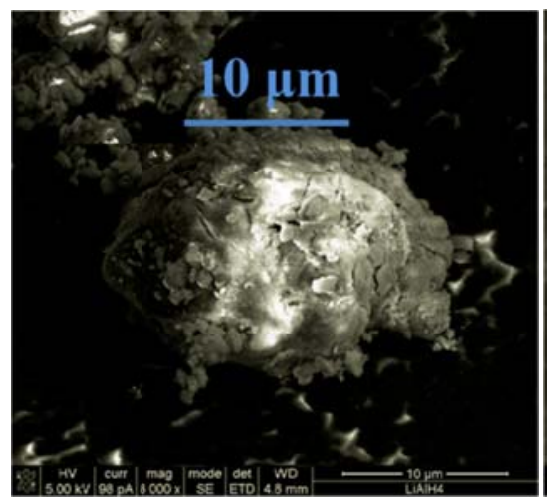

(a)

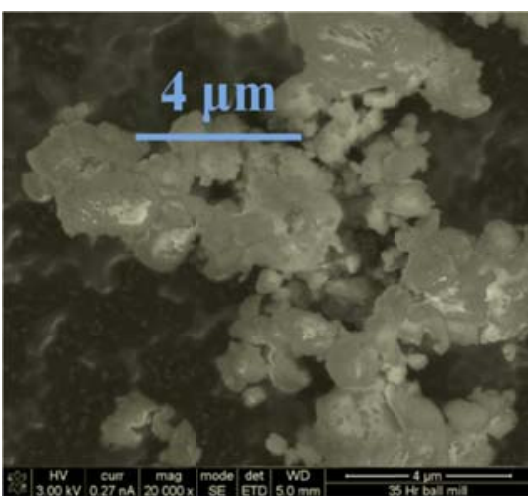

(b)

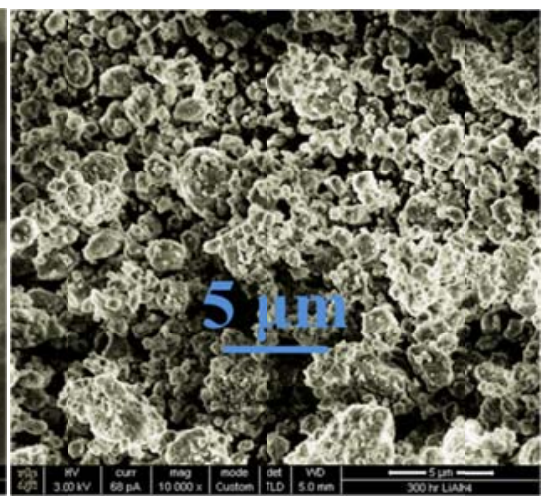

(c)

Figure 5. SEM images of $\mathrm{LiAlH}_{4}$ particles after a) 3 hours, b) 35 hours, and c) 300 hours of ball milling

\section{RDX Casting Results}

A sample batch of paraffin/RDX fuel was cast with 48 grams of paraffin and 2 grams of RDX in approximately $15 \mathrm{~mL}$ of dimethylformamide. After following the procedure outlined in the "Method of Approach" section, the RDX particles were observed and photographed before allowing the melted paraffin to solidify. One of these images is shown in Fig. 6. 


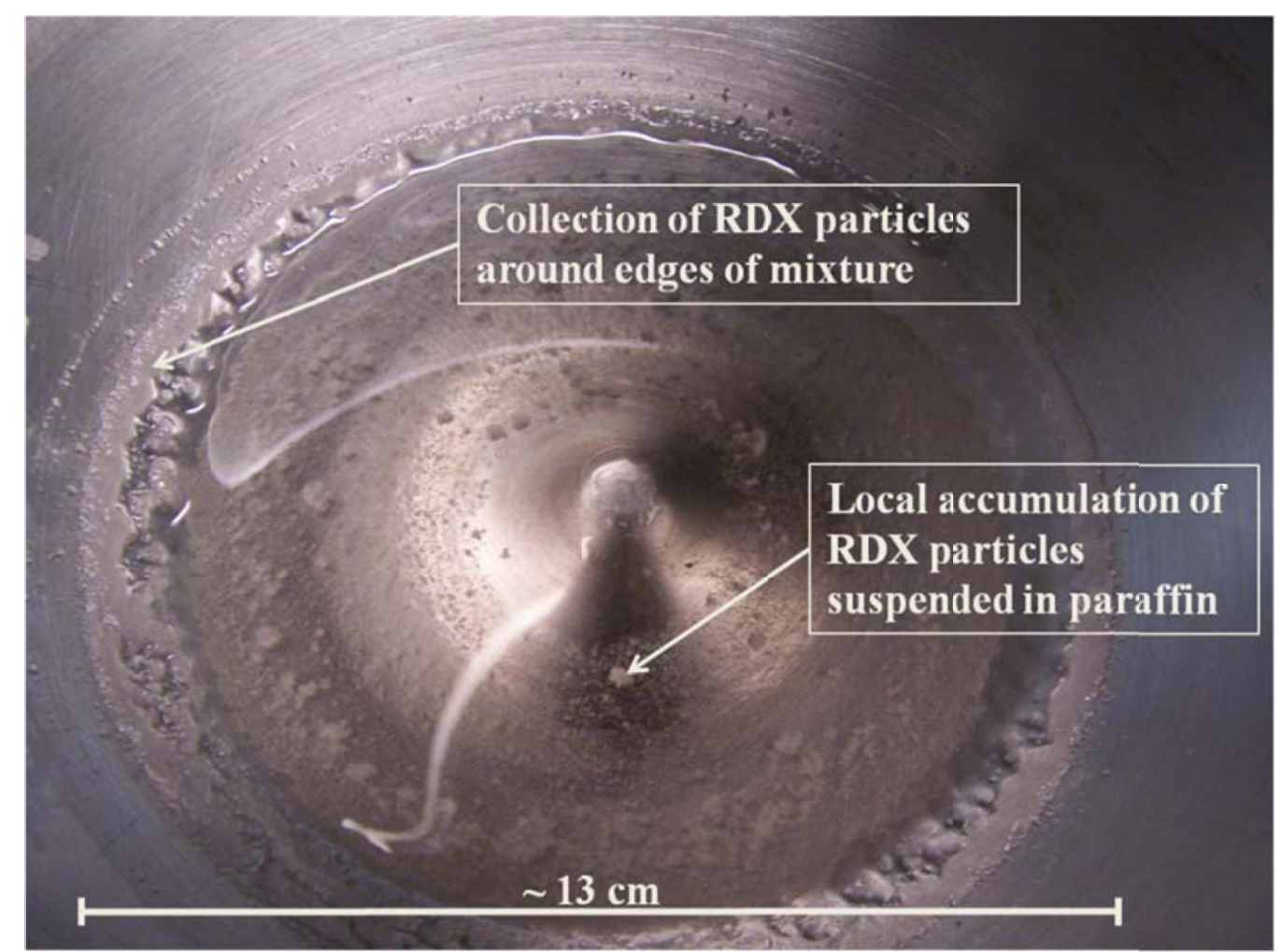

Figure 6. Photograph of paraffin fuel sample containing RDX particles in the mixing bowl after removal of mixing blades

As shown in Fig. 6, the RDX particles nucleated out of the DMF, but the size of the particles is large, and the dispersion of the particles in the melted paraffin was poor. Because the DMF was evaporated out of the paraffin slowly, it allowed DMF/RDX solution to become only slightly supersaturated over time. This is visible in Fig. 7 (generated from Antoine equation parameters $^{14}$ ), as "Cast Condition 2." This slow boiling process resulted in large RDX particles. In order to reduce the particle size, one possible route is to decrease the boiling time, by dropping the pressure in the vacuum chamber to bring the DMF to a significantly superheated state, causing rapid boiling. However, in an earlier attempt to boil off the DMF ("Cast Condition 1 " in Fig. 7), the pressure in the chamber was reduced to a point where the boiling point of the DMF was 20 to $30{ }^{\circ} \mathrm{C}$ below the temperature of the paraffin, causing undesirable violent boiling of DMF due to superheating. To generate small particles, without violent boiling, a median approach must be used. The DMF must be allowed to bubble and boil rapidly, but not to the point where it becomes a violent reaction. 


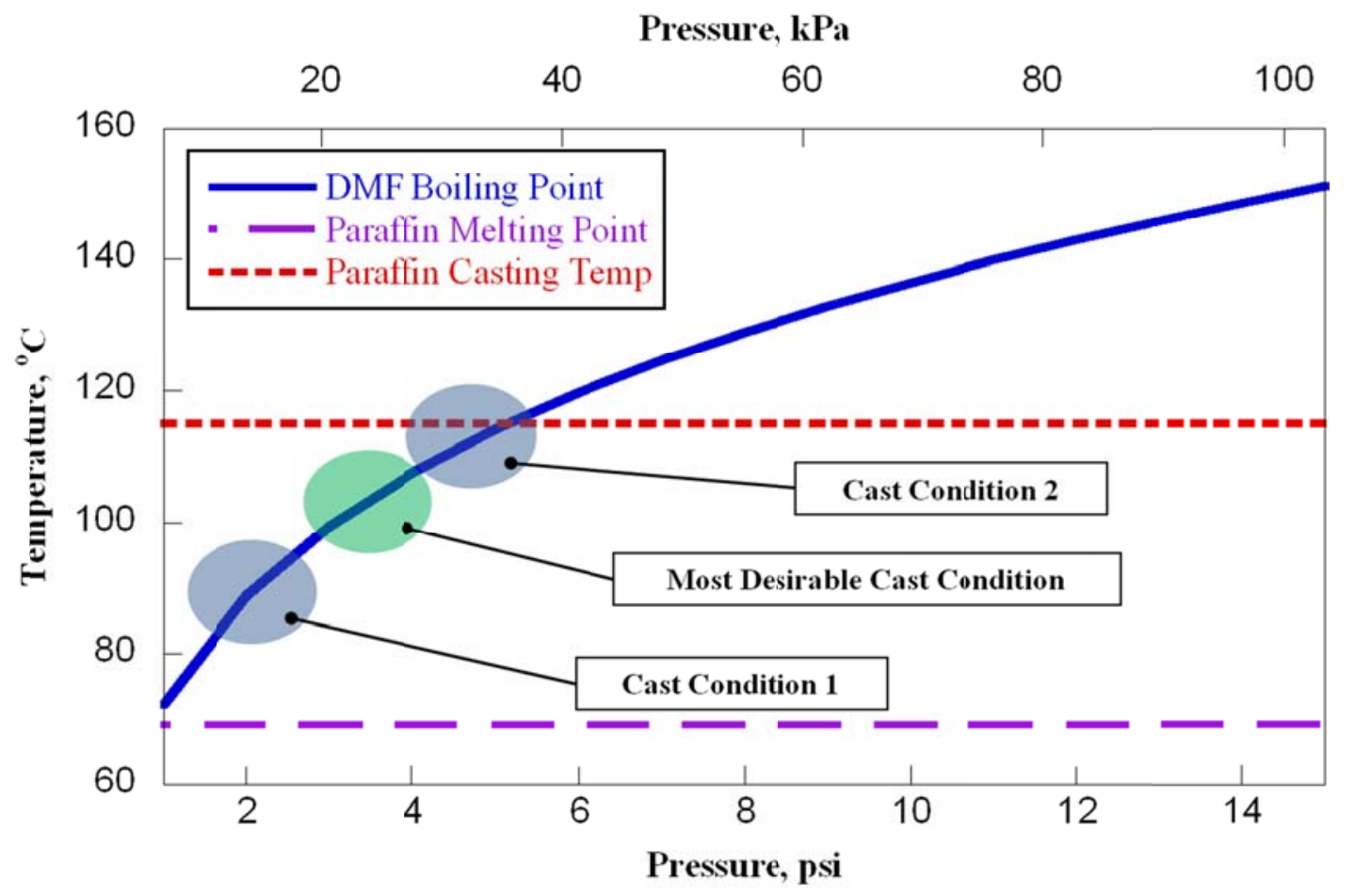

Figure 7. Plot of dimethylformamide boiling point as a function of pressure with SOP casting temperature and melting point of paraffin

\section{MWNT Casting Results}

Throughout the cast processes for various samples of paraffin wax containing different concentrations of MWNT, it was noted that higher weight percentages of MWNT caused a significant increase in the viscosity of the melted fuel. In addition, at higher concentrations of MWNT, sonication became more difficult as large volumes of toluene were required. For example, to debulk enough MWNT necessary to generate one solid fuel grain for testing in the LGCP hybrid rocket motor, approximately $1.5 \mathrm{~L}$ of toluene was used during sonication. Even with this large amount of toluene, after sonication, and after pouring the wax into the hybrid rocket motor, there was a large amount of settled nanotubes. The agglomeration of the nanotubes inside of the paraffin wax can be seen in Fig. 8, with two different samples. It should be noted that when $4 \mathrm{wt} \%$ MWNT or $8 \mathrm{wt} \%$ MWNT is stated, this corresponds to the amount initially added to the toluene prior to sonicating; it is likely that the total concentration of nanotubes in the mixture is lower than the stated value. This is due to losses in the casting process (i.e. nanotubes getting stuck to mixer bowl, beakers, mixing blades, etc). 


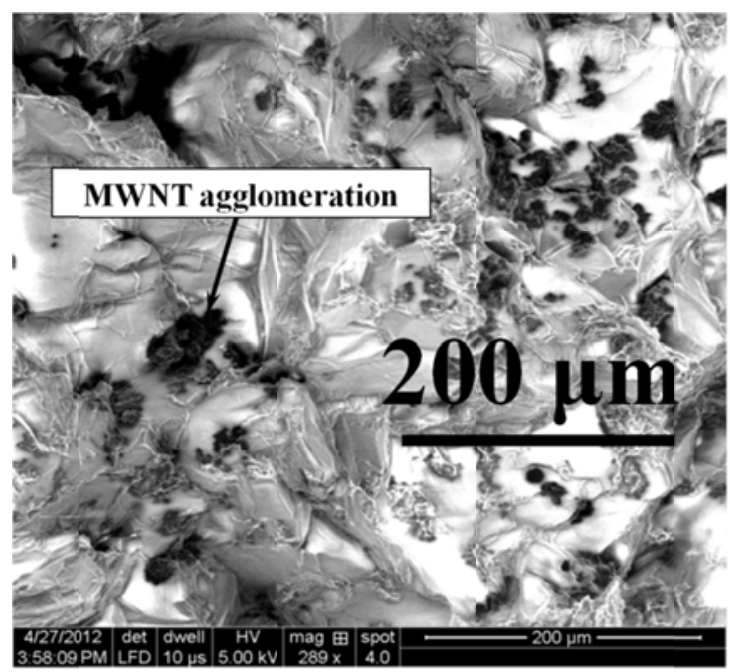

(a)

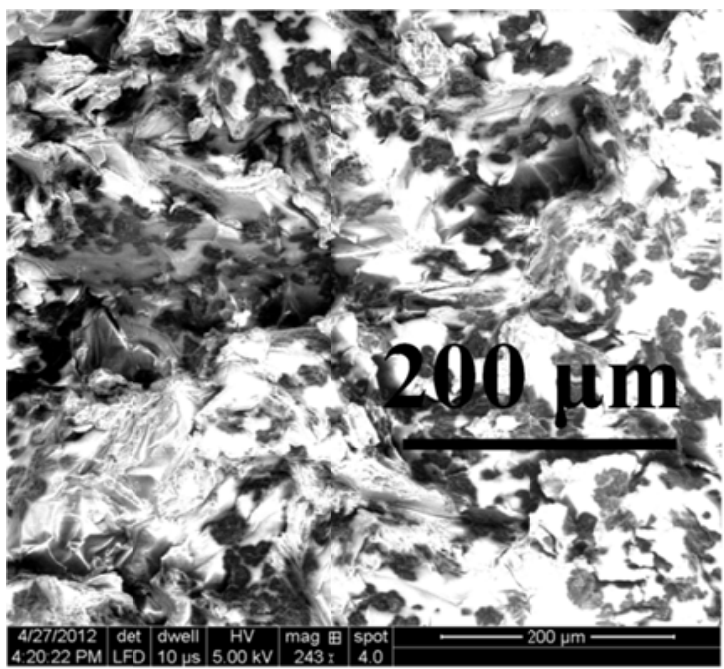

(b)

Figure 8. SEM images of broken surfaces of paraffin wax with a) $4 \mathrm{wt} \%$ MWNT and b) 8 wt \% MWNT showing dispersed MWNT but with local clumping

In the images above, surface charge buildup appears as local bright spots. In order to reduce the amount of surface charge buildup and improve image quality, the sample shown in Fig. 9 was sputter coated with gold and palladium particles. This close-up image, with improved image quality, is of a fuel sample containing $8 \mathrm{wt} \%$ MWNT in paraffin wax.

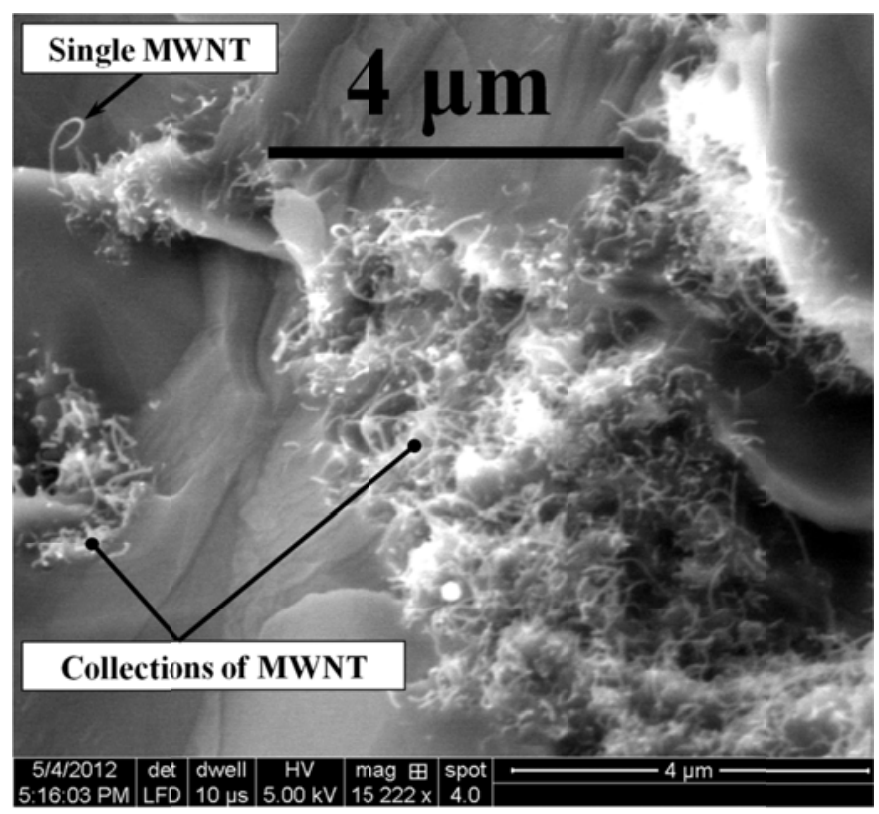

Figure 9. Close-up SEM image of paraffin fuel sample with $8 \mathrm{wt} \%$ MWNT, coated with gold and palladium for better image quality and reduced surface charge buildup

It can be seen in Fig. 9 that the MWNT (light colored strings) appear bundled in most areas. There is still some charge buildup on the surface of the sample. The bundling of MWNT is most likely due to stirring of the paraffin/toluene/MWNT mixture while toluene is boiled out. This stirring can take several hours before toluene is fully removed. Another possibility is that 
the MWNT are not fully dispersed in toluene during sonication, because sonication time is limited by toluene breakdown. Therefore, the use of a wand-type sonicator to simply sonicate the MWNT in the paraffin is required. This could provide good mixing of the MWNT and also debulk the nanotubes in the process, while eliminating the need for toluene.

\section{Hybrid Rocket Motor Test Results}

Various fuel formulations were tested in the LGCP hybrid rocket motor in this study, including different pure paraffin formulations as baselines, $4 \mathrm{wt} \% \mathrm{MWNT}$ in paraffin, $5 \mathrm{wt} \%$ $\mathrm{LiAlH}_{4}$ in paraffin, and $10 \mathrm{wt} \% \mathrm{LiAlH}_{4}$ in paraffin. A photograph of an LGCP motor firing is shown in Fig 10.

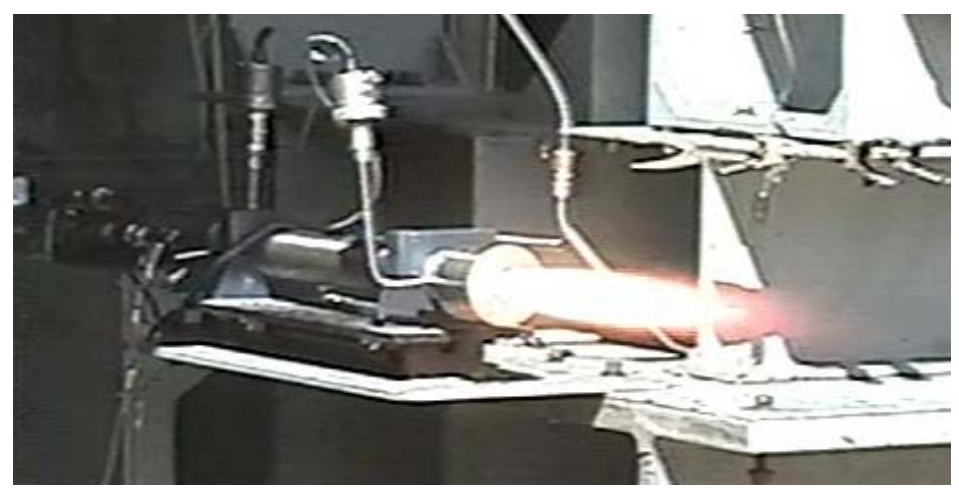

Figure 10. Photograph of LGCP hybrid rocket motor tested with a pure paraffin fuel grain manufactured by the Aerospace Corporation.

In a previous study conducted by PSU and the Aerospace Corporation team members, non-negligible amounts of $\mathrm{LiAlH}_{4}$ in paraffin wax were deposited in the downstream sections of the hybrid rocket setup (i.e., graphite transition section and nozzle). Due to these accumulations, the tests were run at similar conditions, with initial oxidizer mass fluxes of approximately 220 $\mathrm{kg} / \mathrm{m}^{2}$-s with chamber pressures typically between 150 and $250 \mathrm{psig}(1.03$ and $1.72 \mathrm{MPa}) .{ }^{8} \mathrm{In}$ this test series, the amount of deposited fuel on the downstream sections of the hybrid rocket motor was found to be negligible. There was still a thin film of particles which thinly coated the inside of the transition section, but it was not an appreciable mass. However, upon submerging the transition section in water, it was found to bubble slowly. This indicated that some form of $\mathrm{LiAlH}_{4}$ was still unreacted in the downstream components of the motor, since $\mathrm{LiAlH}_{4}$ is highly reactive with water. A set of typical pressure-time traces is given in Fig. 11. 


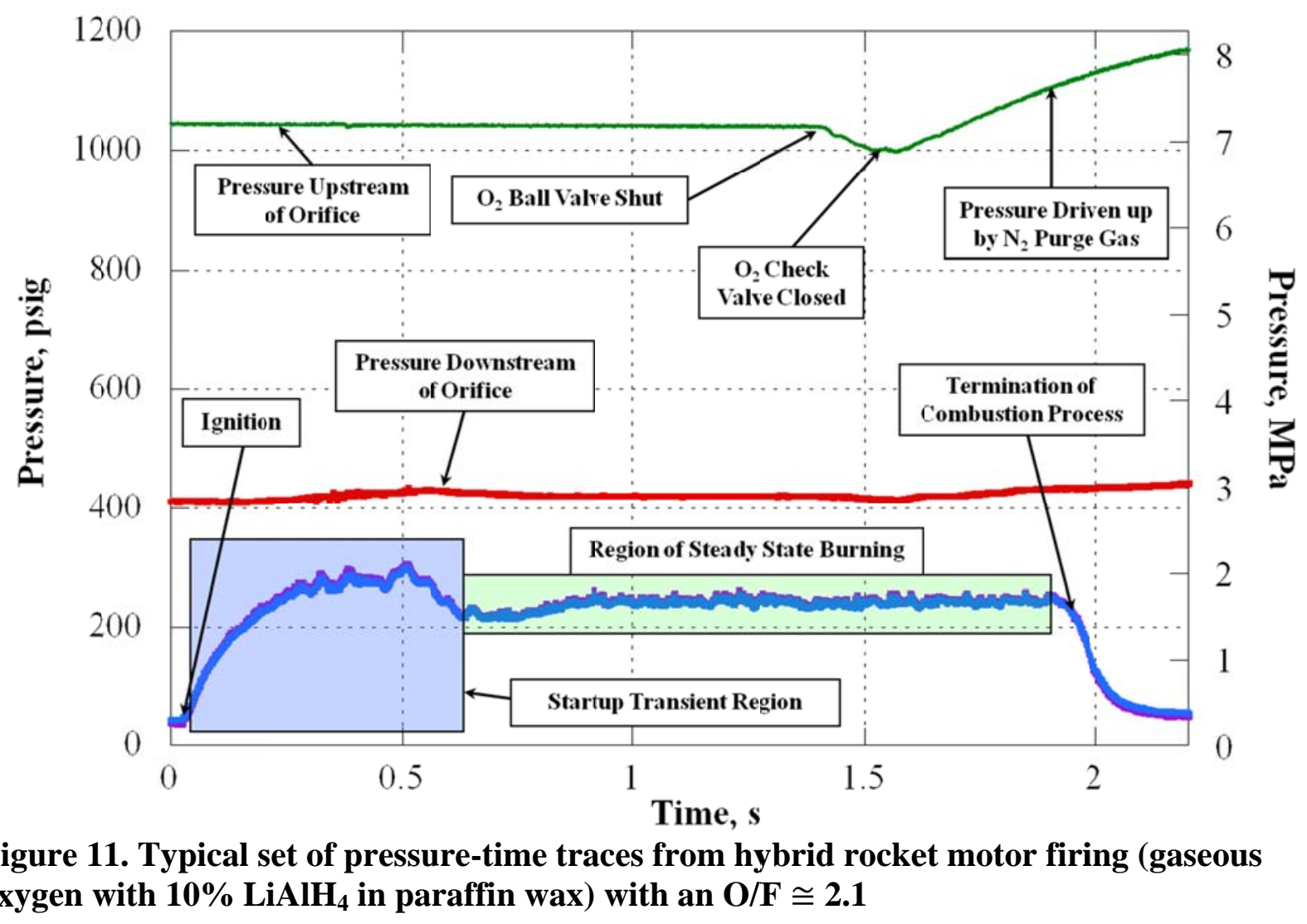

The pressure-time traces shown in Fig. 11 are indicative of a typical motor firing with steady burning behavior. Ignition takes place just after time $=0$, and combustion terminates at approximately 1.9 seconds. The average chamber head pressure during steady state burning was $245 \mathrm{psig}(1.69 \mathrm{MPa})$. It is important to note that after the oxygen run valve closes, there is a slight drop in oxygen before upstream nitrogen forces a check valve closed. Nitrogen purge gas was set at higher pressure than the $\mathrm{O}_{2}$ pressure upstream of the orifice, in order to close this check valve. Due to the higher pressure, the $\mathrm{N}_{2}$ purge gas overdrives the oxygen into the chamber, although there is little appreciable effect in the $\mathrm{O}_{2}$ pressure downstream of the orifice. Because the HPCL hybrid facility was originally designed for motors with flow rates up to 360 $\mathrm{g} / \mathrm{s}$, many of the valve locations make fast start-up and shut-down timing problematic. Relocation of check valves and overdriving $\mathrm{O}_{2}$ pressure with nitrogen to extinguish combustion addressed these issues. In order to determine the mass flow rate of oxygen, the average upstream pressure (top pressure trace in Fig. 11) from ignition to burnout was used. In general, this value was not appreciably affected by the overdrive from nitrogen.

Because the LGCP hybrid rocket motor is used more to determine regression comparisons, the delay in ball valve timing and motor shutoff is not particularly significant. For accurate regression rate calculations, a larger diameter, X-ray transparent hybrid rocket motor is used to obtain instantaneous, real-time regression rate values over longer burn times. A comparison of useable tests from the LGCP is shown below in Fig 12. Since the final port diameter $\left(D_{f}\right)$, described in the "Method of Approach" section, was based on fuel density, it is important to note that the density of $\mathrm{LiAlH}_{4}$ additive fuels was measured to be $0.86 \mathrm{~g} / \mathrm{cm}^{3}$, the density of the Aerospace Corporation's pure paraffin grains was taken as $0.898 \mathrm{~g} / \mathrm{cm}^{3}$, PSU's pure paraffin was taken as $0.86 \mathrm{~g} / \mathrm{cm}^{3}$, and PSU's MWNT additive grains were $0.865 \mathrm{~g} / \mathrm{cm}^{3}$. It 
was noted that on several grains, there was some end burning between the case wall and the fuel. This would affect data by causing the calculated $\mathrm{D}_{\mathrm{f}}$ to be larger than would typically be found. However, when comparing calculated $\mathrm{D}_{\mathrm{f}}$ to measured $\mathrm{D}_{\mathrm{f}}$, the values were typically within $10 \%$ of one another.

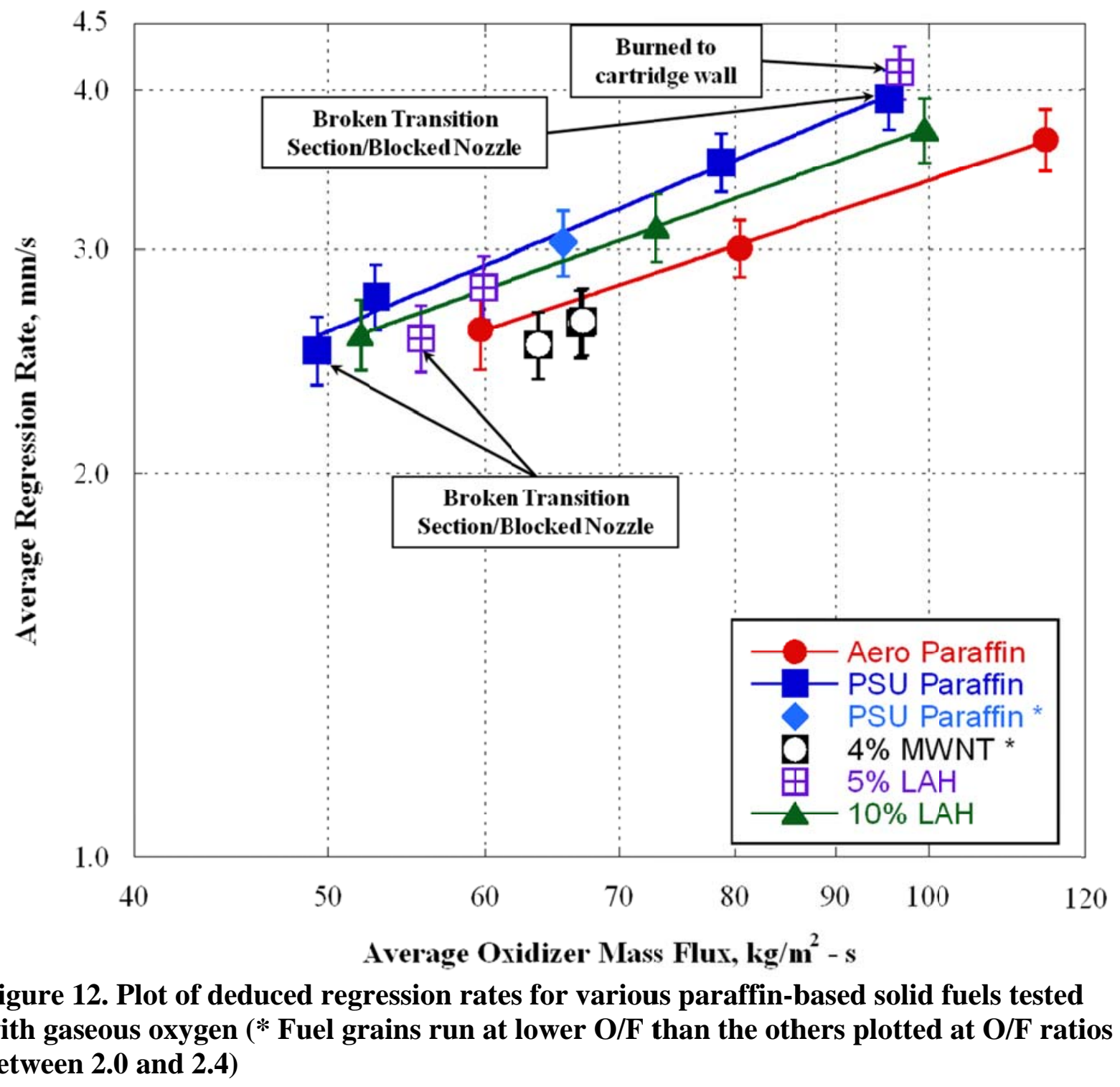

It can be seen from the regression rate comparison plot (Fig. 12) that the Aerospace Corporation paraffin $/ 10 \% \mathrm{LiAlH}_{4}$ fuel grains had a slightly higher regression rate than the pure paraffin fuel grains manufactured by the Aerospace Corporation. The $\mathrm{LiAlH}_{4} /$ paraffin shows approximately a $7-10 \%$ increase over the pure paraffin wax between average oxidizer mass flux values of 60 and $100 \mathrm{~kg} / \mathrm{m}^{2}$-s. Some of this is increase in regression rate could be due to the slightly lower measured density of $\mathrm{LiAlH}_{4}$-doped paraffin fuel; however, as shown in Fig. 13, mass burn rates for paraffin $/ 10 \% \mathrm{LiAlH}_{4}$ fuel grains are still higher than the baseline paraffin grains. The PSU paraffin has an uncharacteristically high regression rate, which is explained by the low density that was measured from the fuel grains. When compared in Fig. 13, PSU's baseline paraffin had only slightly higher mass burn rates than the Aerospace paraffin. Low 
density grains have the tendency to burn faster. This is indicative of casting procedures which allow for the paraffin to keep air in the fuel matrix or simply the grade of paraffin used. This likely occurs after spinning on the lathe and reheating prior to the subsequent pour. Either the pour temperature is too low, or the heat soak (prior to pouring the second layer) is not deep enough, and surface bubbles and imperfections are not melted away.

It should also be noted from the regression rate graph (Fig. 12) that formulations marked with a "*" in Fig. were labeled as such because they were run at lower $\mathrm{O} / \mathrm{F}$ ratios $(1.5-1.75)$. It was expected that fuel grains containing 4\% MWNT would have slightly reduced burn rates due to the amount of graphite in the grain. MWNT increase conductivity to the subsurface layers of the fuel grain, possibly reducing the surface temperature of the burning fuel, resulting in decreased regression rate. Although the regression rate was slightly slower, it is possible that the MWNT could replace carbon black or chemical dies in fuel grain formulations, providing the same radiation heat transfer benefits of stopping any subsurface reaction, while also delivering improved mechanical properties. The inclusion of energetic additives in addition to MWNT is another possibility to improve both the mechanical properties of the paraffin and the mass burn rate and density. Addition of MWNT to the fuel grain would tend to reduce the overall density of the solid-fuel grains due to the lower density of carbon compared to paraffin wax.

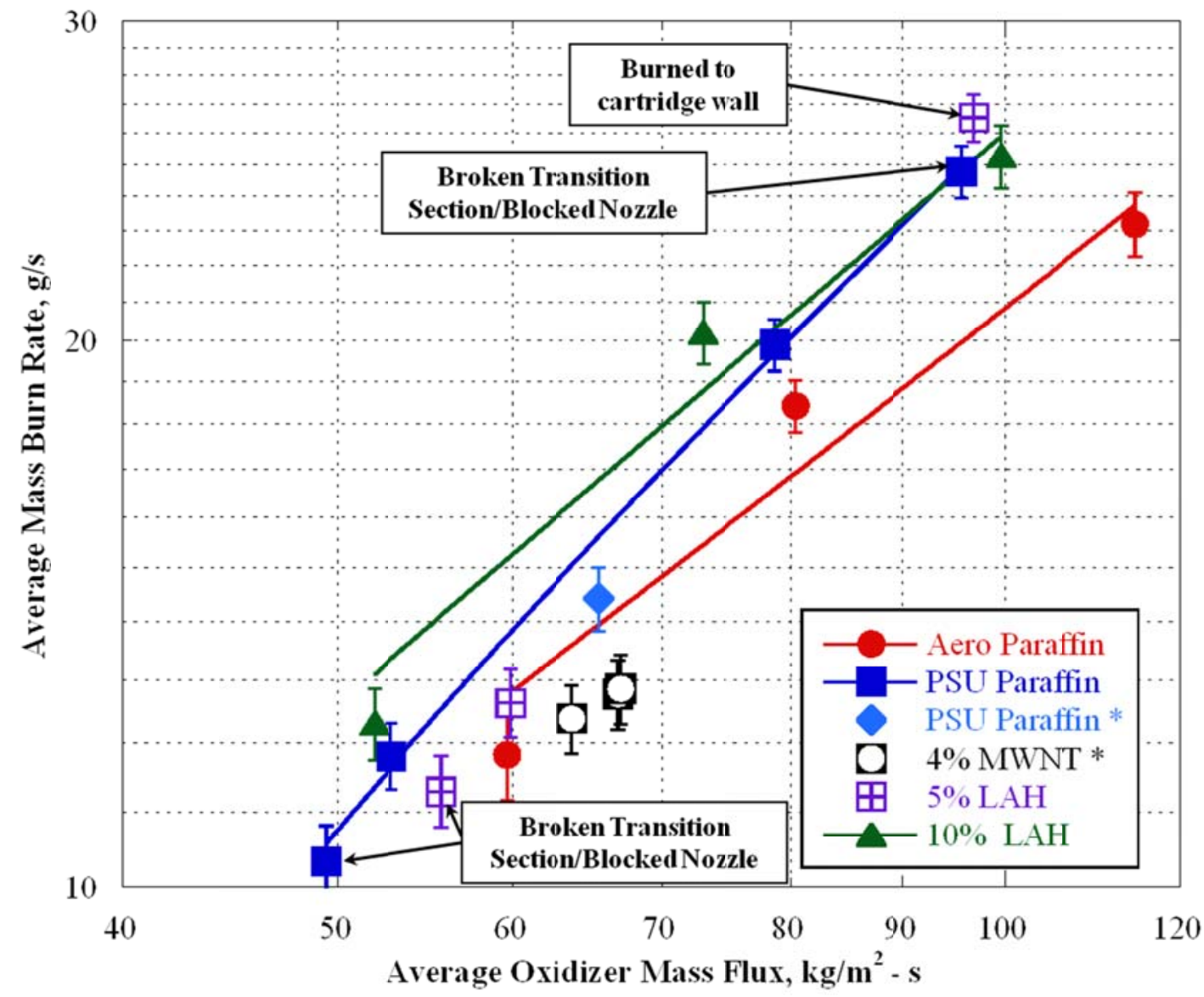

Figure 13. Plot of deduced mass burn rates for various paraffin-based solid fuels tested with gaseous oxygen (* Fuel grains run at lower $\mathrm{O} / \mathrm{F}$ than the others plotted at $\mathrm{O} / \mathrm{F}$ ratios between 2.0 and 2.4) 
If not otherwise noted in Fig. 12 and Fig. 13, and aside from one test where fuel grain which burned into the phenolic cartridge wall $\left(5 \% \mathrm{LiAlH}_{4}\right)$, all other tests were run with $\mathrm{O} / \mathrm{F}$ values between around 2 to 2.4. For the Aerospace Corporation manufactured grains, the $\mathrm{O} / \mathrm{F}$ for the pure paraffin tests was around 2.3 to 2.4 , while the $\mathrm{O} / \mathrm{F}$ for the grains doped with $10 \%$ $\mathrm{LiAlH}_{4}$ was between 2 and 2.2. This is satisfactory because, as shown in Fig. 1, peak $\mathrm{I}_{\mathrm{sp}}$ for 10\% $\mathrm{LiAlH}_{4}$ occurs at a slightly lower $\mathrm{O} / \mathrm{F}$ value than for pure paraffin. Regression rate data in Fig. 11 also supports previous assertions that increases in $\mathrm{LiAlH}_{4}$ additive allow a hybrid rocket to run at lower $\mathrm{O} / \mathrm{F}$ ranges than pure paraffin without sacrificing $\mathrm{I}_{\mathrm{sp}}$. This is most clear when looking at the data points from pure Aerospace Corporation paraffin and $10 \% \mathrm{LiAlH}_{4}$ which show a regression rate of $\sim 2.6 \mathrm{~mm} / \mathrm{s}$. The $10 \% \mathrm{LiAlH}_{4}$ paraffin was run at lower oxidizer mass flux, but achieve the same regression rate. It can be concluded that increases in $\mathrm{LiAlH}_{4}$ content can improve regression rate of the paraffin fuel; however, the described tests are a limited test sequence. In order to achieve a more complete test matrix, fuel grains containing $15-25 \%$ submicron $\mathrm{LiAlH}_{4}$ could be processed and tested to better observe the effect of this beneficial additive. Load cell data was not conclusive when analyzed for large differences in thrust between the $\mathrm{LiAlH}_{4} /$ paraffin motors compared to pure paraffin motors. This was because chamber pressures between $\mathrm{LiAlH}_{4}$-doped paraffin and pure paraffin fuel grains were very similar. Chamber pressures between the two tests at each condition were within 5\% of each other.

\section{SUMMARY AND CONCLUSIONS}

1) $\mathrm{LiAlH}_{4}$ particle size was significantly reduced over 300 hours of ball milling and fuel grains with 0,5 , and $10 \mathrm{wt} \%$ of $\mathrm{LiAlH}_{4}$ showed excellent homogeneity. Examination of the post-fired samples of the paraffin fuel grains with $\mathrm{LiAlH}_{4}$ revealed highly uniform center port geometry.

2) A $10 \mathrm{wt} \%$ addition of $\mathrm{LiAlH}_{4}$ to paraffin wax showed a $7-10 \%$ increase in regression rate over that of the baseline paraffin fuel cast by Aerospace Corporation, although part of this increase in burn rate is likely due to lower density of the $\mathrm{LiAlH}_{4}$-doped paraffin wax compared to pure paraffin. Mass burn rate comparisons confirmed a burn rate increase for grains doped with $\mathrm{LiAlH}_{4}$ over pure paraffin.

3) Solid-fuel samples with MWNT were imaged using an SEM, and revealed uniform MWNT distribution, although the MWNT were often clumped together. Changes to the casting procedure are required to better disperse the MWNT in the paraffin. The paraffin $/ 4 \mathrm{wt} \%$ MWNT fired in the LGCP hybrid rocket motor demonstrated consistent burning, although regression rate was slightly lower than the baseline PSU paraffin fuel. This reduction in regression rate is believed to be caused by the increase in thermal conductivity of the solid fuel with MWNT additives. When the energy transfer to the subsurface region is faster, the fuel surface temperature may be reduced, therefore resulting in reduced mass burning rates.

4) A novel RDX/paraffin casting procedure was developed and demonstrated. RDX particles nucleating out of the dimethylformamide/RDX solution were too large, likely due to a slow boiling process. Improvements to the process were identified to achieve more uniform properties in paraffin wax. 


\section{Future Work}

1) Additional testing is planned for test firings with paraffin fuels containing $20 \mathrm{wt} \%$ $\mathrm{LiAlH}_{4}$, in order to generate more systematic data to better characterize the enhancement of regression by this energetic additive.

2) Cast new grains for use in a larger hybrid rocket motor system at PSU's High Pressure Combustion Lab. The X-ray Transparent Center-perforated (XTC) hybrid rocket motor allows for real time regression analysis which is far more accurate in determining regression rates for various fuel formulations.

3) Cast new batches of RDX with smaller, more evenly distributed particles in the paraffin matrix by drawing a deeper vacuum to cause supersaturation of RDX in the boiling dimethylformamide solvent.

4) Create paraffin/MWNT samples for mechanical testing at the University of TexasAustin. Also, cast new grains with carbon black to compare with similar percentages of MWNT.

\section{ACKNOWLEDGEMENTS}

This work was supported (in part) by a NASA Office of the Chief Technologist's Space Technology Research Fellowship for Daniel Larson's M.S. program.

\section{REFERENCES}

\footnotetext{
${ }^{1}$ Chiaverini, M. J. and Kuo, K. K., Fundamentals of Hybrid Rocket Combustion and Propulsion. A.I.A.A., Inc. Reston, VA, 2007.

${ }^{2}$ Karabeyoglu, M. A.; Altman, D..; Cantwell, B.; "Combustion of Liquefying Hybrid Propellants: Part 1, General Theory" Journal of Propulsion and Power, Vol. 18, No. 3, May-June 2002, pp. 610-620.

${ }^{3}$ Karabeyoglu, M. A.; Cantwell, B. J.; Altman, D. "Development and Testing of Paraffin-Based Hybrid Rocket Fuels", AIAA-2001-4503, 37th AIAA/ASME/SAE/ASEE Joint Propulsion Conference and Exhibit, Salt Lake City, Utah, July 2001.

${ }^{4}$ Kuo, K. K., Risha, G. A., Evans, B. J., and Boyer, E., "Potential Usage of Energetic Nano-sized Powders for Combustion and Rocket Propulsion," Synthesis, Characterization and Properties of Energetic/Reactive Nanomaterials, MRS-Materials Research Society, Vol. 800, pp. 3-14, 2004.

${ }^{5}$ Risha, G. A., Boyer, E., Evans, E., and Kuo, K. K., "Characterization of Nano-Sized Particles for Propulsion Applications," Characterization and Properties of Energetic/Reactive Nanomaterials, Materials Research Society , ed. W. Wilson, et. al., Pittsburgh, PA, Invited Paper, December 2003.

${ }^{6}$ DeSain, J. D., Curtiss, T. J., Metzler, K. M., and Brady, B. B., "Testing Hypergolic Ignition of Paraffin Wax/ LiAlH4 Mixtures," AIAA-2010-6636, 46th AIAA/ASME/SAE/ASEE Joint Propulsion Conference and Exhibit, Nashville, Tennessee, July 25-28, 2010.

${ }^{7}$ DeSain, J. D., Rikimaru, D. K., Dorman, K., Hashimoto, T. A., Curtiss, T. J., and Brady, B. B., "Hypergolic Ignition of a Paraffin Wax/Gaseous O2 Hybrid Rocket Test Motors," Aerospace Report No. ATR-2011(8402)-1, 2011.

${ }^{8}$ Larson, D. B., et al., "Characterization of the Performance of Paraffin/LiAlH4 Solid Fuels in a Hybrid Rocket System," AIAA 2011-5822, 47th AIAA/ASME/SAE/ASEE Joint Propulsion Conference and Exhibit, San Diego, CA, July 31 - August 3, 2011.

${ }^{9}$ Andreasen, A., Vegge, T., and Pedersen, A.S., "Dehydrogenation kinetics of as=received and ball-milled $\mathrm{LiAlH}_{4}$," Journal of Solid State Chemistry 178 (2005) 3672-3678, Elsevier, 2005

${ }^{10}$ Meyer, R., Köhler, J., Homburg, A., Explosives, Sixth Completely Revised Edition. Wiley-VCH Verlag GmbH \& Co., Veinheim, 2007.
} 
${ }^{11}$ Lund, G. K. Starrett, D., and Jensen, K. C., "Development and Lab-Scale Testing of a Gas Generator Hybrid Fuel in Support of the Hydrogen Peroxide Hybrid Upper Stage Program." Paper 2001-3244, 37 $7^{\text {th }}$

AIAA/ASME/SAE/ASEE Joint Propulsion Conference and Exhibit, Salt Lake City, Utah (2001).

${ }^{12}$ Markopoulos, P., and Abel, T., "Development and Testing of a Hydrogen Peroxide Hybrid Upper Stage Propulsion System." Paper 2001-3243, 37 ${ }^{\text {th }}$ AIAA/ASME/SAE/ASEE Joint Propulsion Conference and Exhibit, Salt Lake City, Utah (2001).

${ }^{13}$ Sitzmann, M. E., et al, "Solubilities of High Explosives: Removal of High Explosive Fillers from Munitions by Chemical Dissolution." Naval Ordnance Laboratory, AD-773 078, NOLTR 73-186, White Oak, MD, 1973.

${ }^{14}$ Gopal, R. and Rizvi, S. A., "Antoine Equation Parameters" in NIST Chemistry WebBook, NIST Standard Reference Database Number 69, Eds. Linstrom, P. J. and Mallard, W. G., National Institute of Standards and Technology, Gaithersburg, MD, 20899, <http://webbook.nist.gov>, (retrieved 17 Nov. 2011).

${ }^{15}$ DeSain, J. D., Brady, B. B., Metzler, K. M., Curtiss, T. J., and Albright, T. V., "Tensile Tests of Paraffin Wax for Hybrid Rocket Fuel Grains," AIAA 2009-5115, 45th AIAA/ASME/SAE/ASEE Joint Propulsion Conference and Exhibit, Denver, Colorado, August 2-5, 2009.

${ }^{16}$ Wang, J., Xie, H., Xin, Z., "Thermal Properties of Paraffin Based Composites Containing Multi-Walled Carbon Nanotubes.” Thermochimica Acta 488 (2009) 39-42, Elsevier, 2009.

${ }^{17}$ Luo, Z.P., Koo, J.H., "Quantitative Study of the Dispersion Degree in Carbon Nanofiber/Polymer and Carbon Nanotube/Polymer Nanocomposites," Materials Letters, Volume 62, Issue 20, pp 3493-3496, July 31, 2008.

${ }^{18}$ Tate, J.S., Kabakov, D., Koo, J.H., "Carbon/Phenolic Nanocomposites: Ablative Applications," SAMPE Journal, Volume 47, Issue 3, pp 36-43, May-June, 2011.

${ }^{19}$ Cataldo, F., "Ultrasound-induced cracking and pyrolysis of some aromatic and naphthenic hydrocarbons," Ultrasonics Sonochemixtry 7 (2000) 35-43, Elsevier, 1999.

${ }^{20}$ Karabeyoglu, A. M., Cantwell, B. J., and Zilliac, G., "Development of Scalable Space-Time Averaged regression Rate Expressions for Hybrid Rockets," AIAA 2005-3544, 41 ${ }^{\text {st }}$ AIAA/ASME/ASEE Joint Propulsion Conference, Tucson, AZ, July 2005.

${ }^{21}$ Rothstein, D., Brady, B. B., DeSain, J. D., and Curtiss, T. J., "Reducing Lithium Aluminum Hydride Particle Sizes to Increase Regression Rates in Paraffin Wax Motors," Aerospace Report No. ATR-2011(8402)-6, 2011. 


\section{Formulation, Casting, and Evaluation of Paraffin- Based Solid Fuels Containing Energetic and Novel Additives for Hybrid Rockets}

Daniel B. Larson, Eric Boyer, Trevor Wachs, and Kenneth K. Kuo

The Pennsylvania State University, University Park, PA 16802

John D. DeSain, Thomas J. Curtiss, and Brian B. Brady

The Aerospace Corporation, El Segundo, CA 90245

Russell Borduin and Joseph H. Koo

University of Texas-Austin, Austin, TX 78712

And

George Story

NASA-Marshall Space Flight Center, Huntsville, AL 35811

$9^{\text {th }}$ International Symposium on Special Topics in Chemical Propulsion

July 2012 


\section{Introduction}

- Three solid-fuel additives considered for use in paraffin fuel in hybrid rocket system burning with gaseous $\mathrm{O}_{2}$ :

- Lithium Aluminum Hydride $\left\{\mathrm{LAH}\right.$ or $\left.\mathrm{LiAlH}_{4}\right\}$

- $\mathrm{LiAlH}_{4}$ shown to be pyrophoric with strong acids (e.g., nitric acid)

- Restart on demand without replacement igniters

- Fuel grains manufactured at the Aerospace Corporation

- Cyclotrimethylenetrinitramine $\left\{R D X\right.$ or $\left.\mathrm{C}_{3} \mathrm{H}_{6} \mathrm{~N}_{6} \mathrm{O}_{6}\right\}$

- Energetic additive with potential to increase density specific impulse

- Multi-Walled Carbon Nanotubes \{MWNT\}

- Potential to increase mechanical properties

- Solid-fuel grains tested in a hybrid rocket motor at PSU's High Pressure Combustion Laboratory (HPCL) 


\section{Hybrid rocket pros and cons}

Liquid Propellant Solid Propellant Classic Hybrid

\section{Advantages:}

- Improved safety

- Robustness

- Environmental impact

- Low cost

\section{Disadvantages:}

- Low bulk density

- Low regression rate

- O/F shift

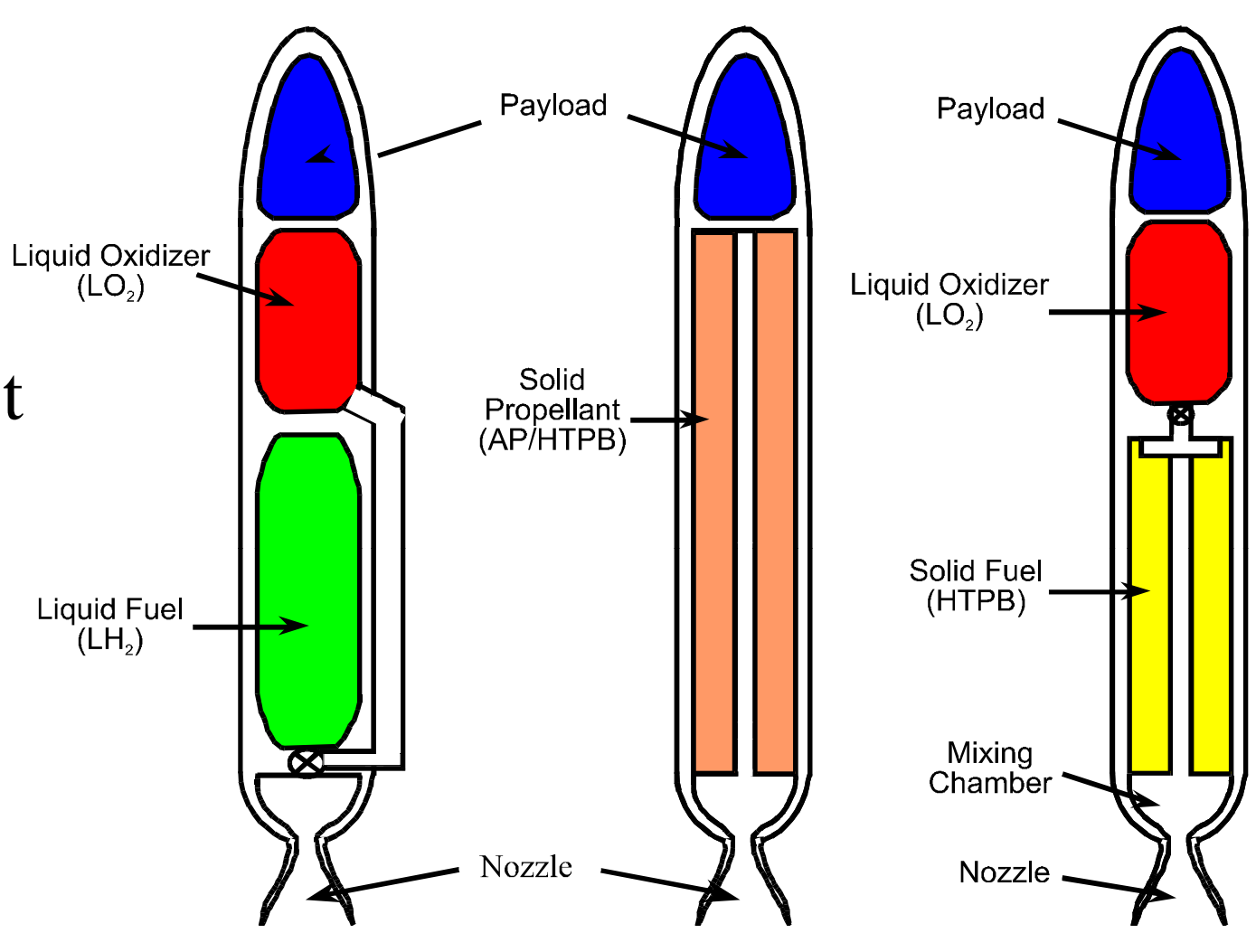

Kuo and Chiaverini, 2005 


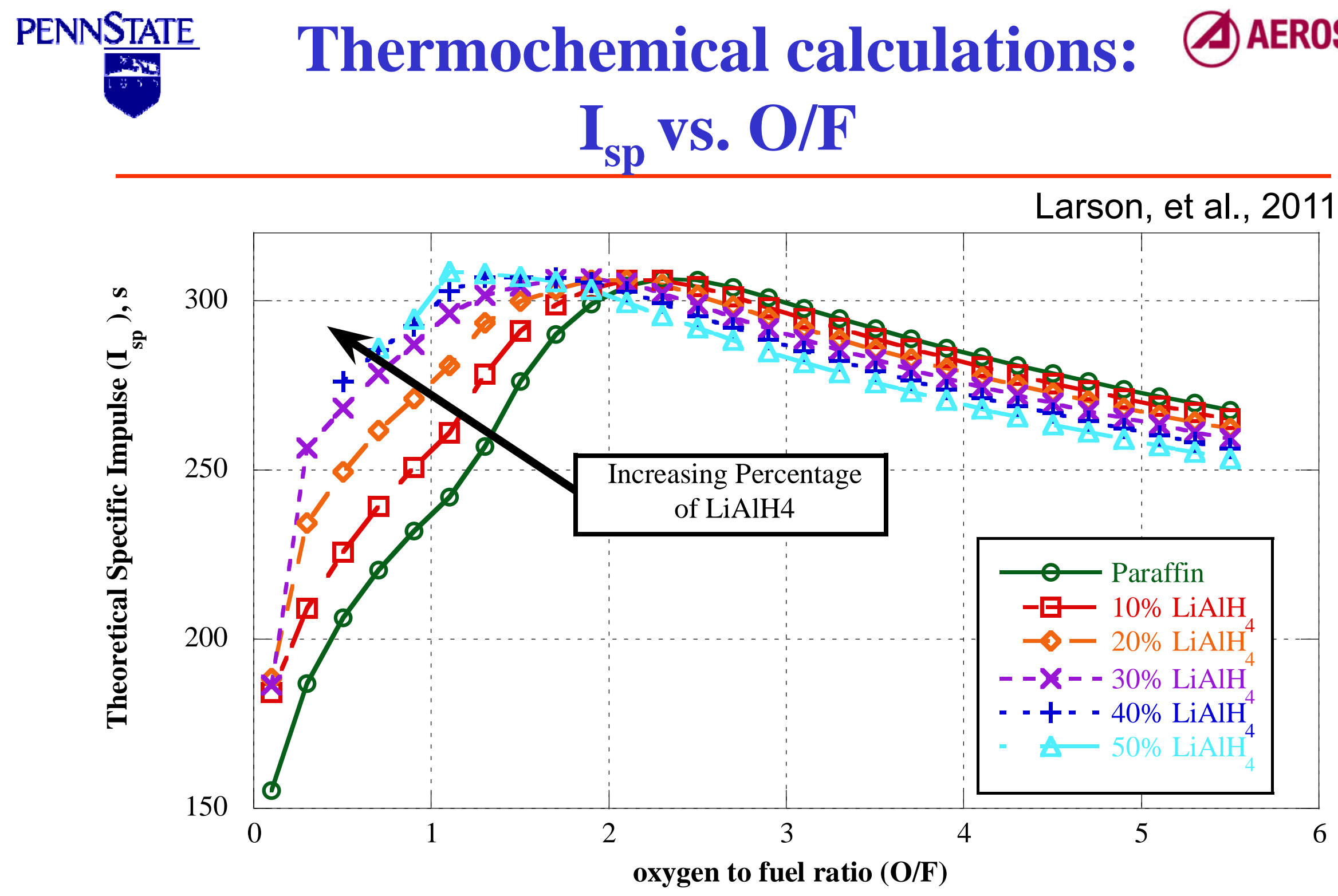

Chamber pressure $=6.9 \mathrm{MPa}$, Nozzle Expansion Ratio $=10$ 


\section{PENNSTATE

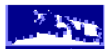 \\ Pressure-time traces for \\ various additives}

Larson, et al., 2011

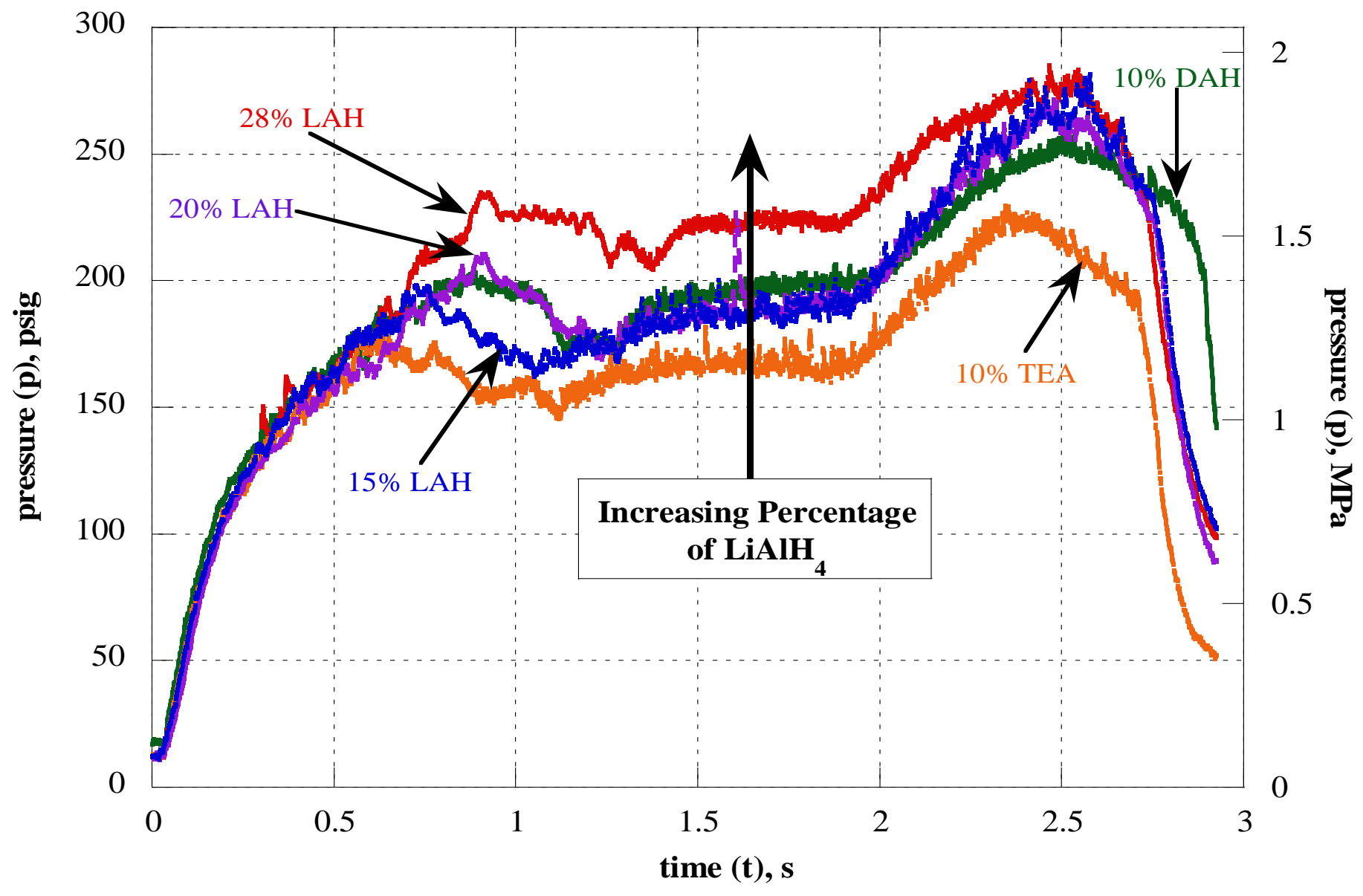

Ignition at time $=0 \mathrm{~s}$ and tests at initial $\mathrm{O}_{2}$ fluxes of $\sim 220 \mathrm{~kg} / \mathrm{m}^{2}-\mathrm{s}$ 


\section{sections of hybrid rocket motor}

- Observed deposition of unburned/unreacted fuel from hybrid motor firings

- Typical results showed several grams of accumulation in downstream sections

- $10 \%-22 \%$ of fuel trapped downstream

- $\mathrm{LiAlH}_{4}$ particles may have been too large

- Particles may have been getting trapped in wax and carried downstream

- Higher melting point wax may allow more complete $\mathrm{LiAlH}_{4}$ particle reaction due to higher temperatures near burning fuel surface

o Thinner melt layer
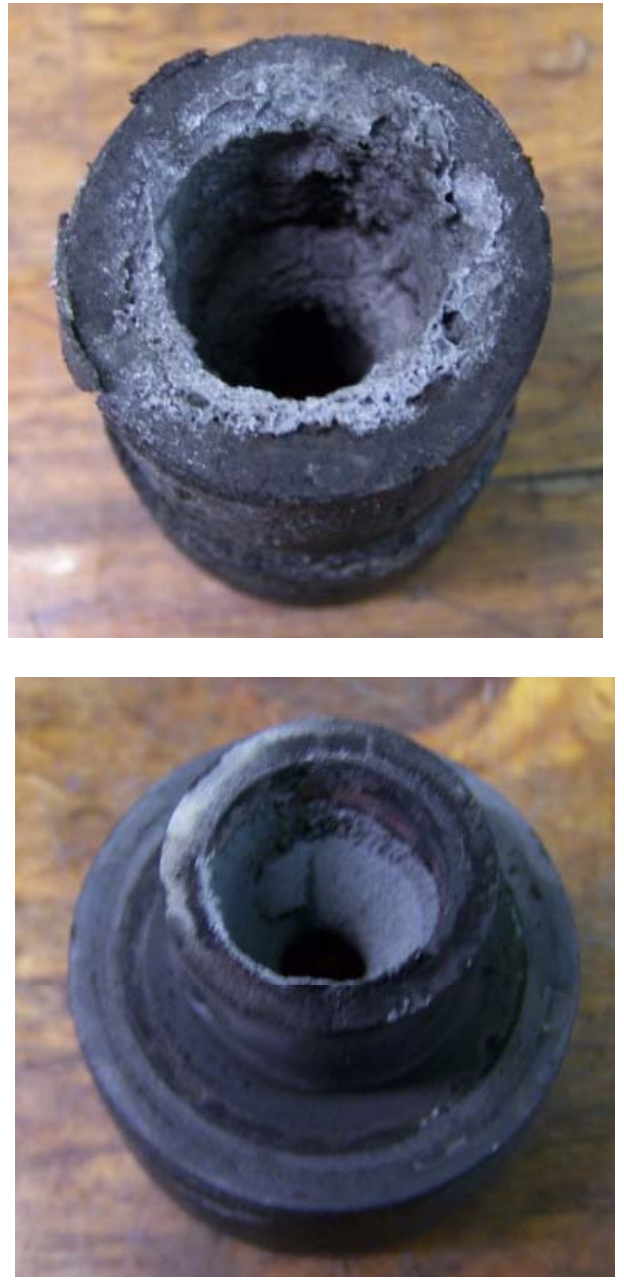

Larson, et al., 2011 


\section{Solid-fuel grain characteristics}

\section{Desirable Features:}

- Homogeneous grain structure

- High repeatability

- P-t trace data

- Consumption rate

- Uniform surface burning

- Complete combustion

- High regression rate

- Structure integrity

\section{Undesirable Features:}

- Voids in grain

- Deposition of fuel in downstream components

- Unreacted additive particles

- Grain delamination prior to or during burn

- Uneven burning

- Low regression rate

- Poor mechanical properties 


\section{Ball-milled $\mathrm{LiAlH}_{4}$ particles}

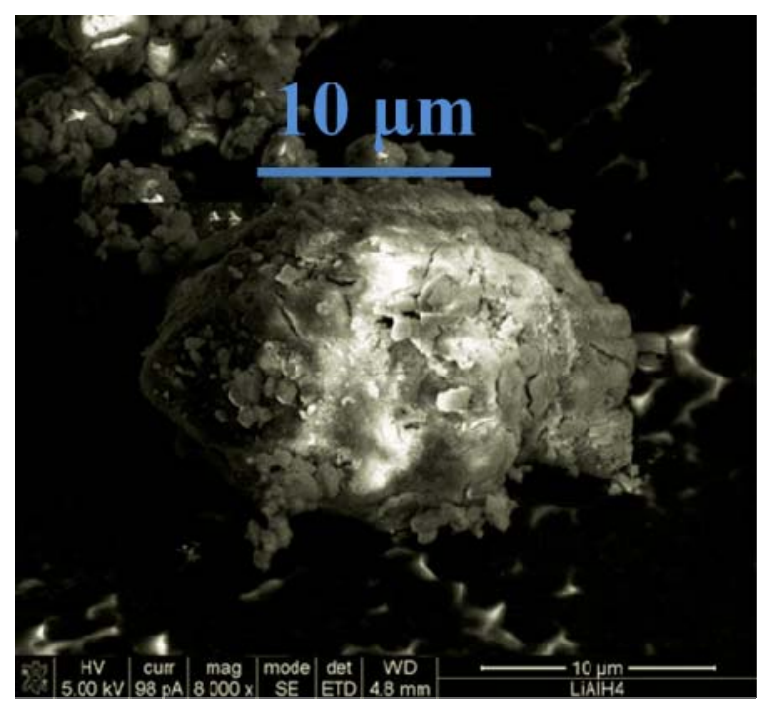

10 hours

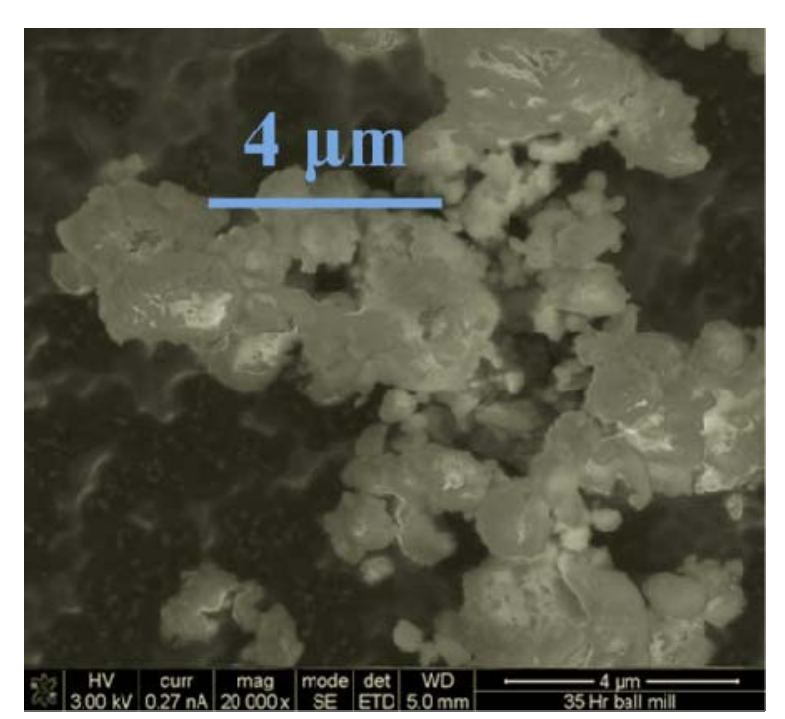

35 hours

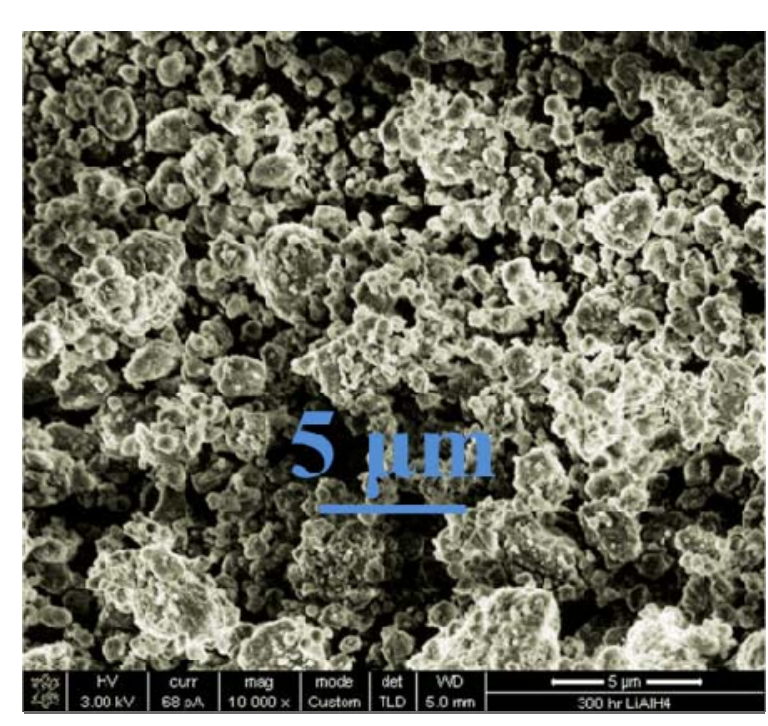

300 hours

- Majority of particles less than $100 \mathrm{~nm}$ after 300 hours

- Many particles have alumina layer

- Could delay or inhibit combustion/particle decomposition 
Larson, et al., 2011

- Wax melted in beaker

- $\mathrm{LiAlH}_{4}$ addition occurred in $\mathrm{N}_{2}$-purged bag

- Mixture was poured into phenolic tube through filling ports on wax motor mold - Spun on lathe @ 400 RPM

- Grains cast in 3 poured layers

- Grains were perforated with a $3 / 8$-inch hole and cut to various lengths

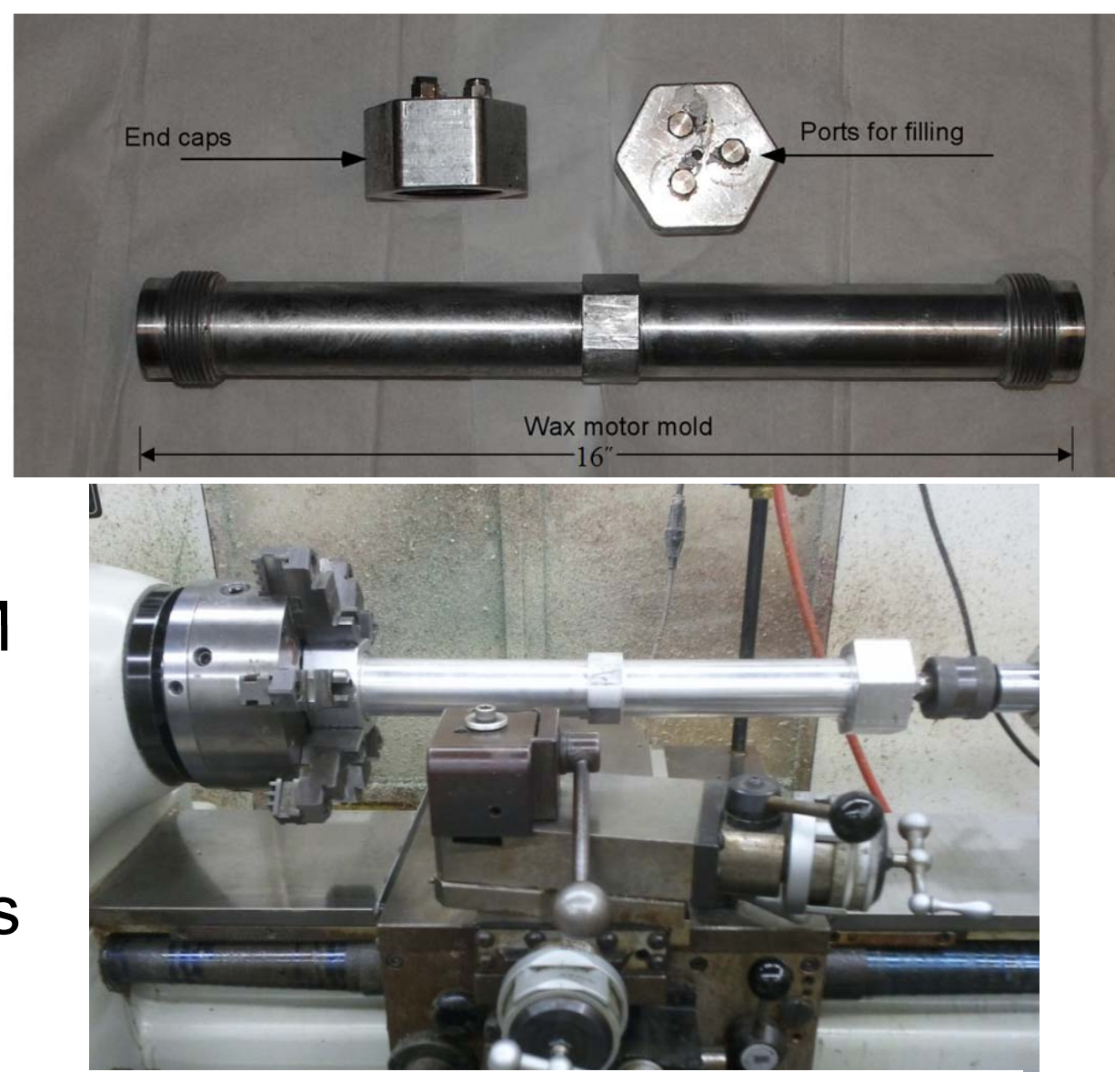

mass percentage of $\mathrm{LiAlH}_{4}$ additive $=\frac{\left(\text { mass of } \mathrm{LiAlH}_{4}\right)}{\left(\text { mass of } \mathrm{LiAlH}_{4}+\text { mass of paraffin wax }\right)} \times 100 \%$ 


\section{PSU fuel grain casting}

- Wax melted in mixing pot

- Environmental chamber can be used with $\mathrm{N}_{2}$ purge or vacuum pump

- MWNT with nitrogen

- RDX with vacuum

- Spun on lathe @ 400 RPM

- Grains cast in 2 poured layers

- Grains were perforated with a 3/8-inch hole and cut to various lengths
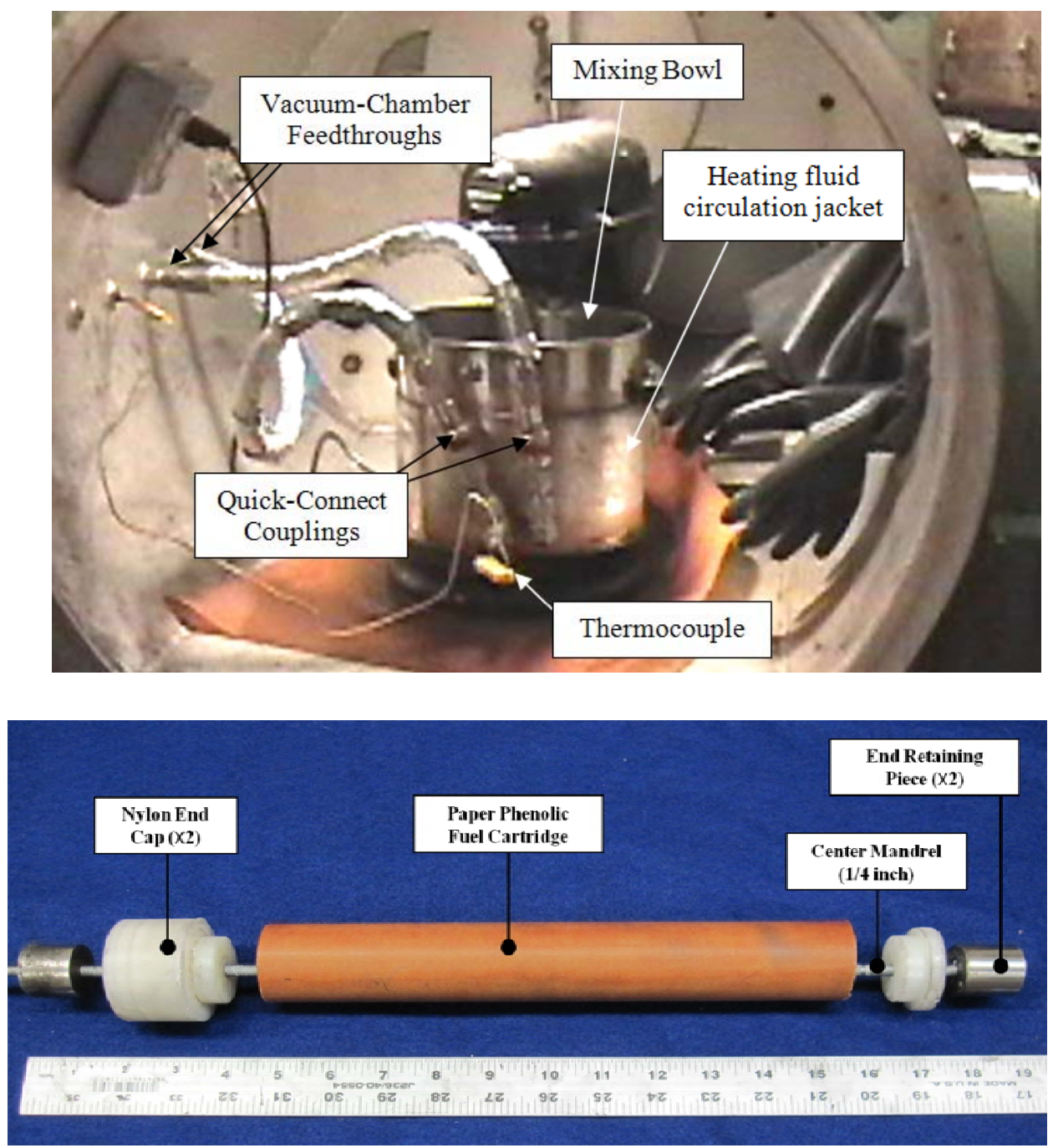


\section{Paraffin/RDX fuel sample casting}

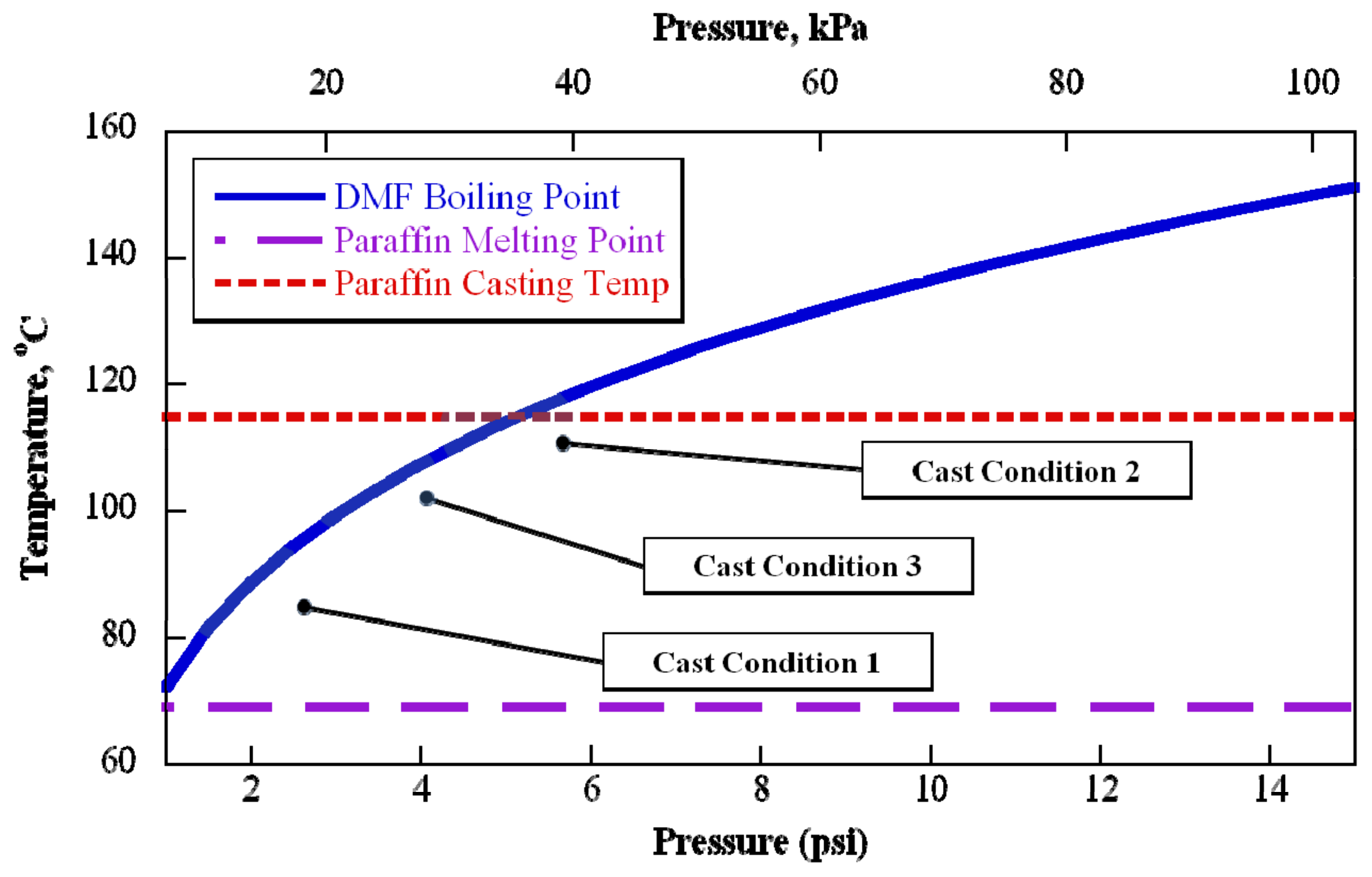




\section{PENNSTATE}

RDX fuel sample casting result

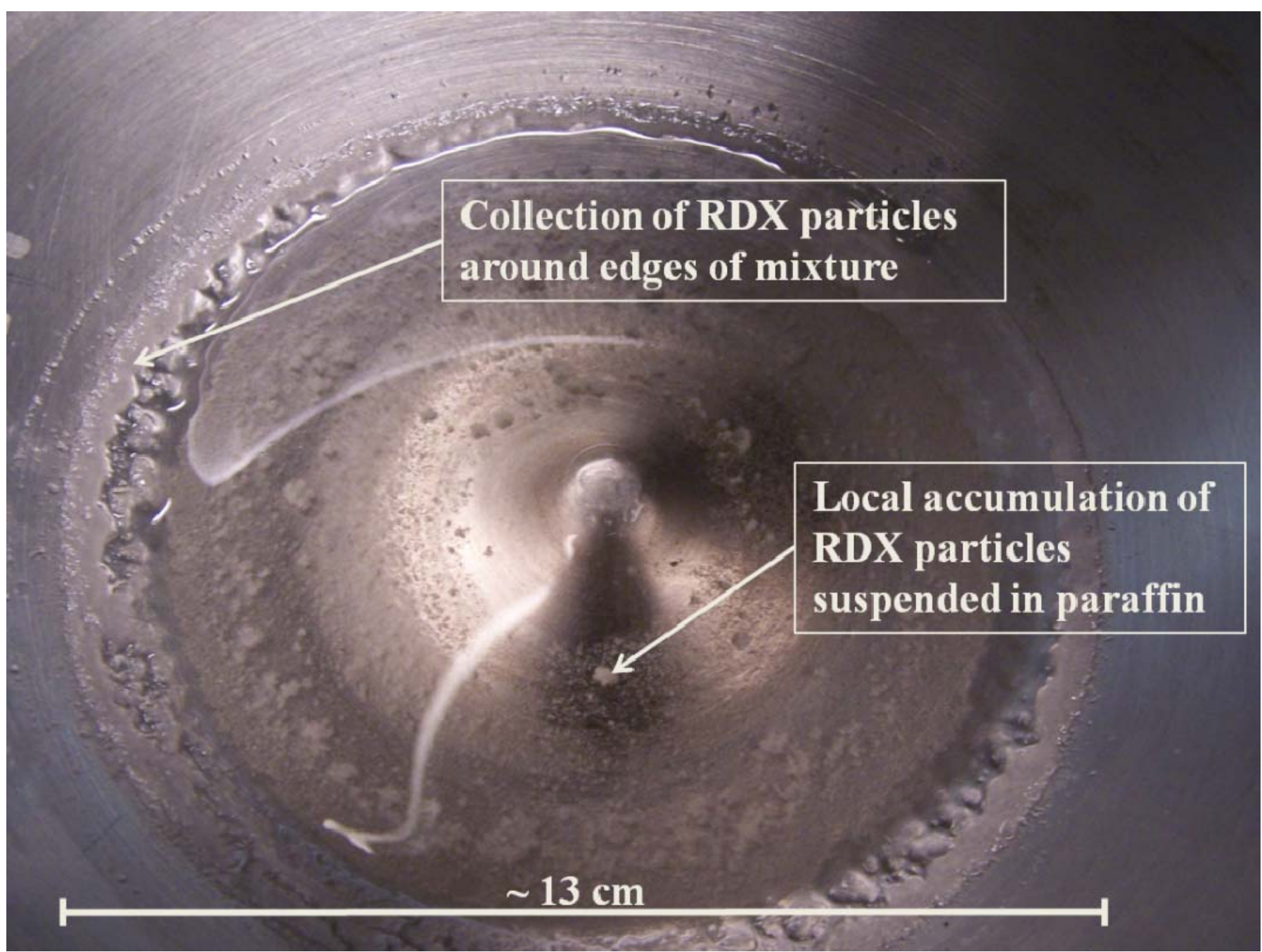




\section{Paraffin/MWNT fuel casting}

- MWNT measured and mixed with toluene

- (100mL toluene / 1-2 grams MWNT)

- Beaker floated in water sonication bath and sonicated for $\sim 20$ mins

- Mixture transferred to melted paraffin (held at $<110^{\circ} \mathrm{C}$ )

- Environmental chamber door closed, nitrogen purge gas flow started

- Paraffin temperature increased above BP of toluene

- Mixed until complete removal of toluene

- Various small fuel samples (<50 grams) sent to Center for Nano and Molecular Science at University of Texas-Austin for TGA, DSC, and SEM tests

- 0\%- $8 \%$ MWNT concentrations

- One solid-fuel grain (paraffin/4\% MWNT) cast for testing in hybrid rocket motor 


\section{Paraffin/MWNT fuel samples}

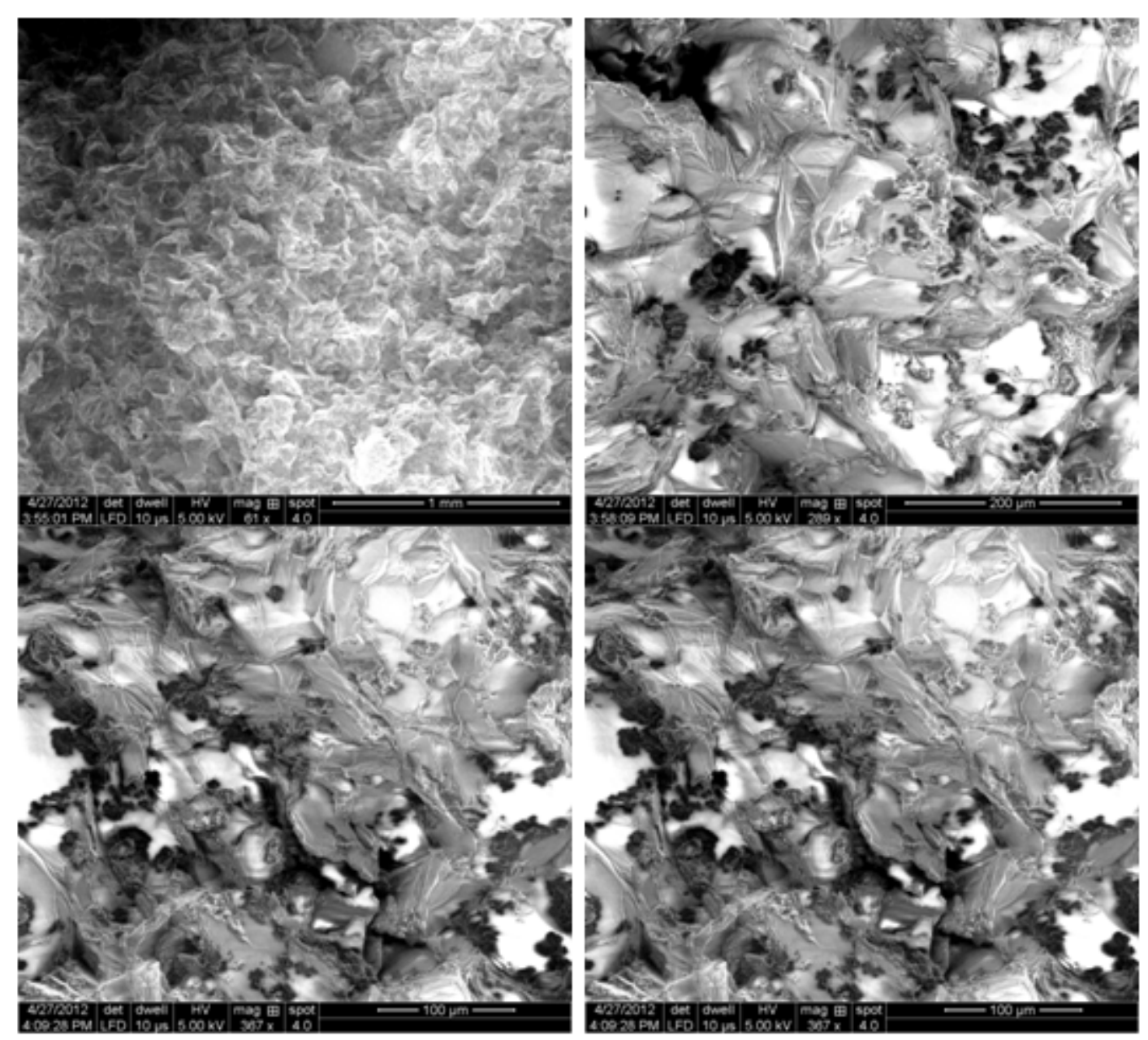

Increasing SEM magnification from $1 \mathrm{~mm}$ to $100 \mu \mathrm{m}$ for paraffin $/ 4 \%$ MWNT sample 


\section{Paraffin/MWNT fuel samples}
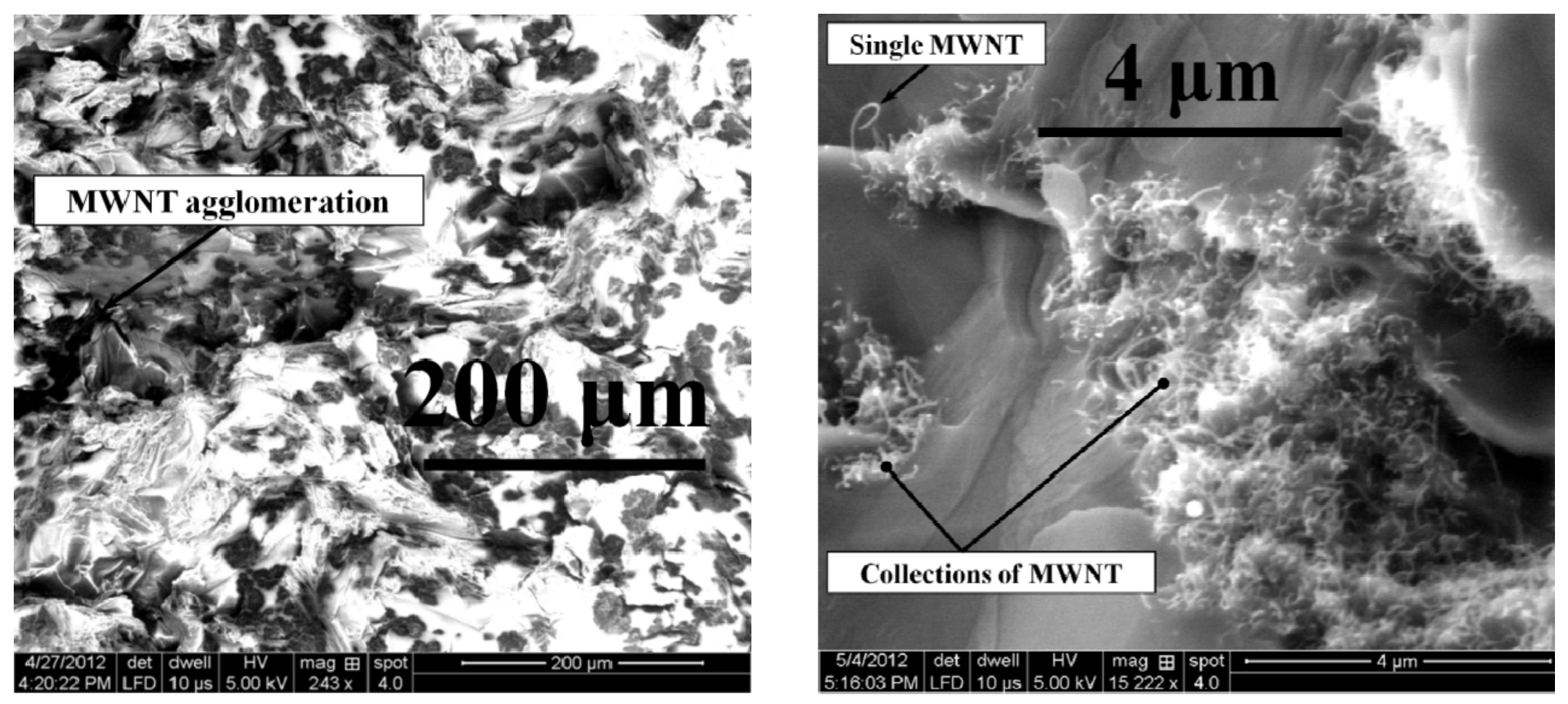

- $8 \%$ MWNT with uncoated (left) and coated (right) surfaces

- MWNT is well distributed, but clumped together 


\section{Hybrid rocket motor firings}

Long-Grain Center-Perforated (LGCP) hybrid rocket motor:

- Cartridge load system for a paper phenolic tube with 38.1$\mathrm{mm}\left(1.5^{\prime \prime}\right)$ diameter and length of $406.4 \mathrm{~mm}\left(16^{\prime \prime}\right)$

- Chamber pressures up to $12 \mathrm{MPa}(1,750 \mathrm{psi})$

- $\mathrm{O}_{2}$ mass flow rates up to $0.36 \mathrm{~kg} / \mathrm{s}(0.8 \mathrm{lbm} / \mathrm{s})$

o Tests in this study:

$>$ Pressure max was $\sim 3.2 \mathrm{MPa}(\sim 465 \mathrm{psi})$

$>\mathrm{O}_{2}$ mass flow rates between 20 and $54 \mathrm{~g} / \mathrm{s}$ $(0.044-0.119 \mathrm{lbm} / \mathrm{s})$

$>$ Average $\mathrm{O}_{2}$ flux $\left(\mathrm{G}_{\mathrm{ox}}\right)$ values between 49 and $115 \mathrm{~kg} / \mathrm{m}^{2}-\mathrm{s}$

- Four pressure transducers (2 on feed system and 2 chamber), load cell, data acquisition system and live video feed for recording tests 


\section{PENNSTATE}

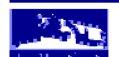

\section{Long-Grain Center-Perforated Hybrid Rocket Motor}

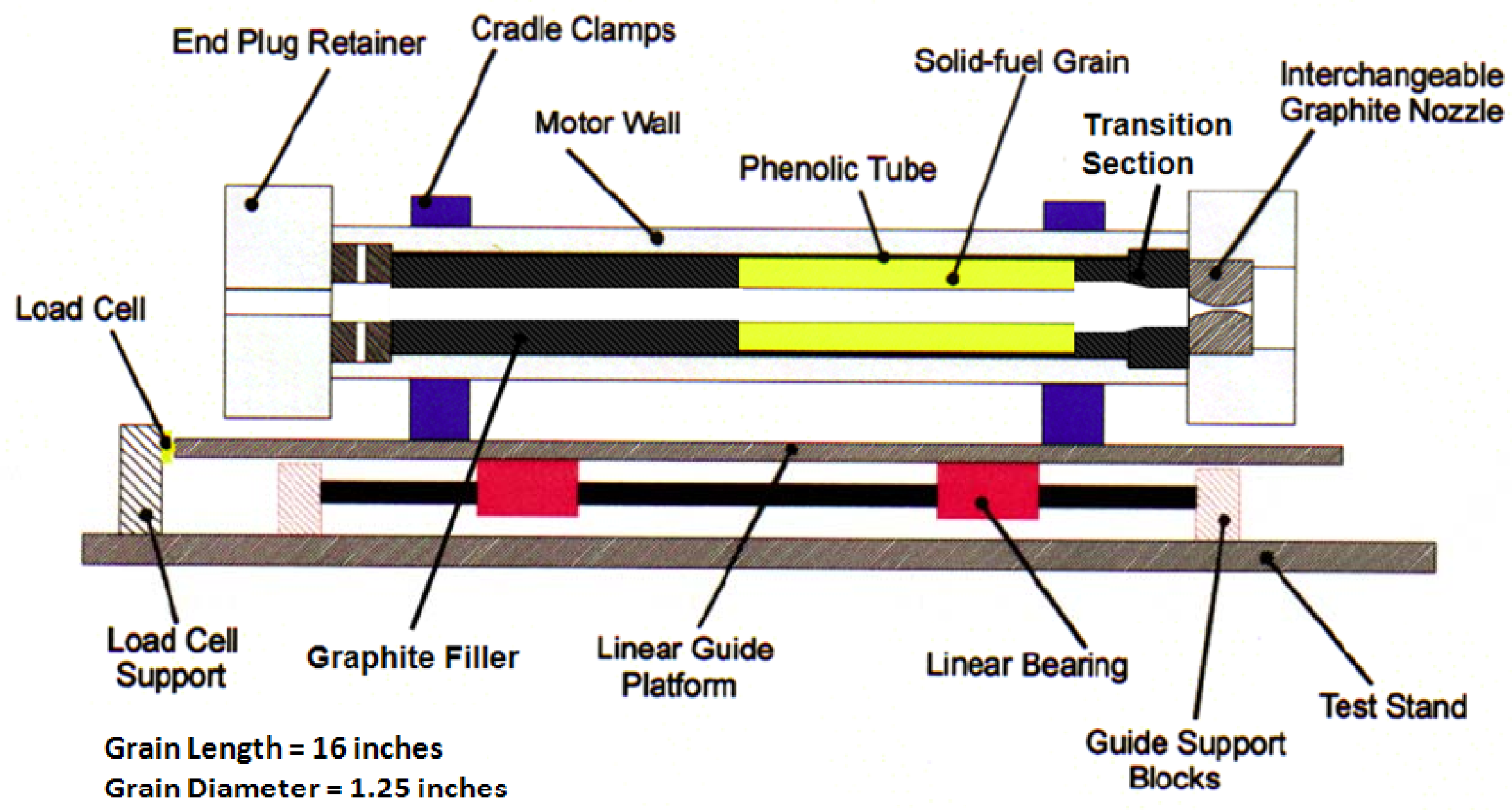




\section{Typical videos of motor firings}

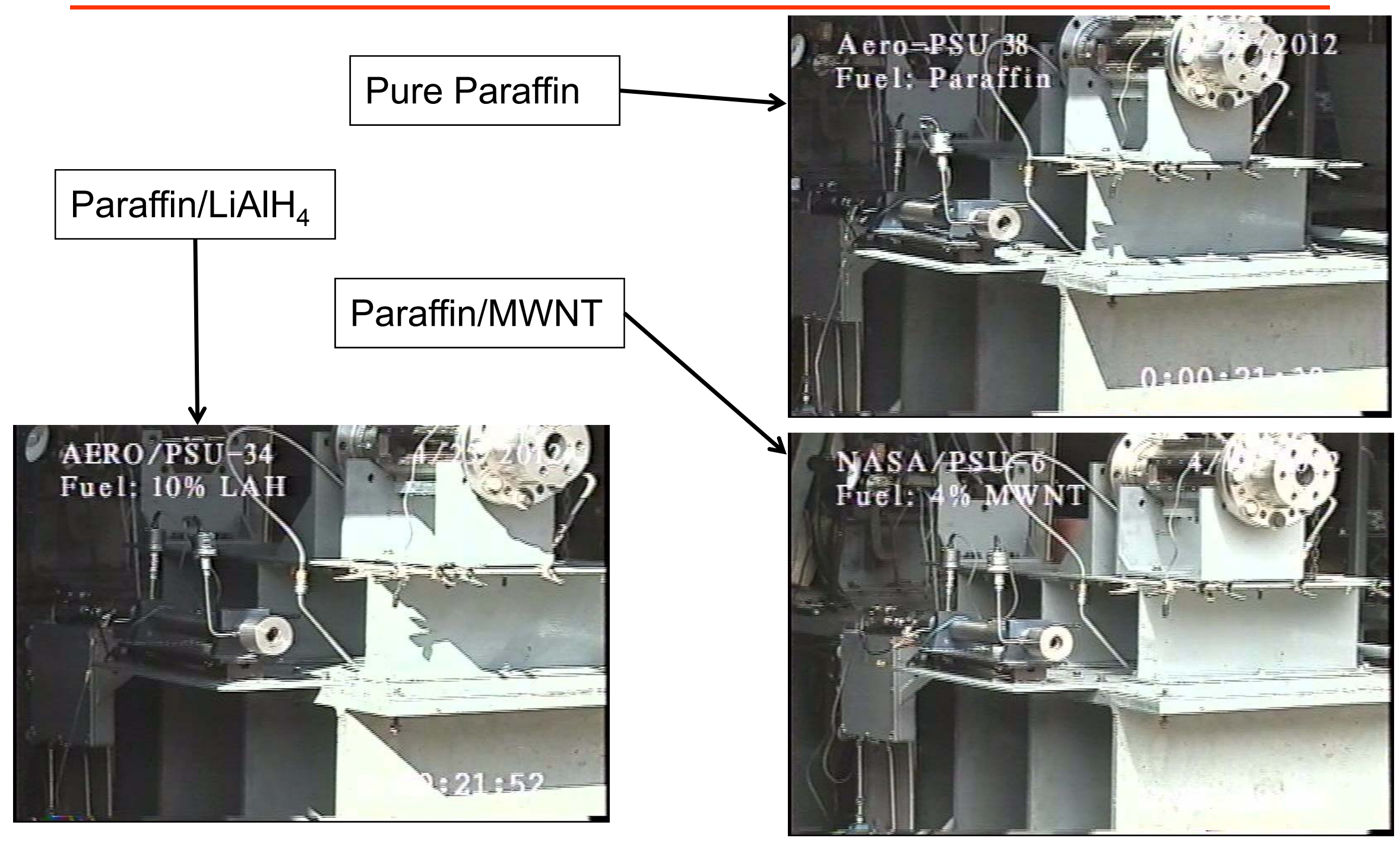




\section{PENNSTATE}

\section{Pressure-time traces from paraffin fuel grain containing $10 \% \mathrm{LiAlH}_{4}$}

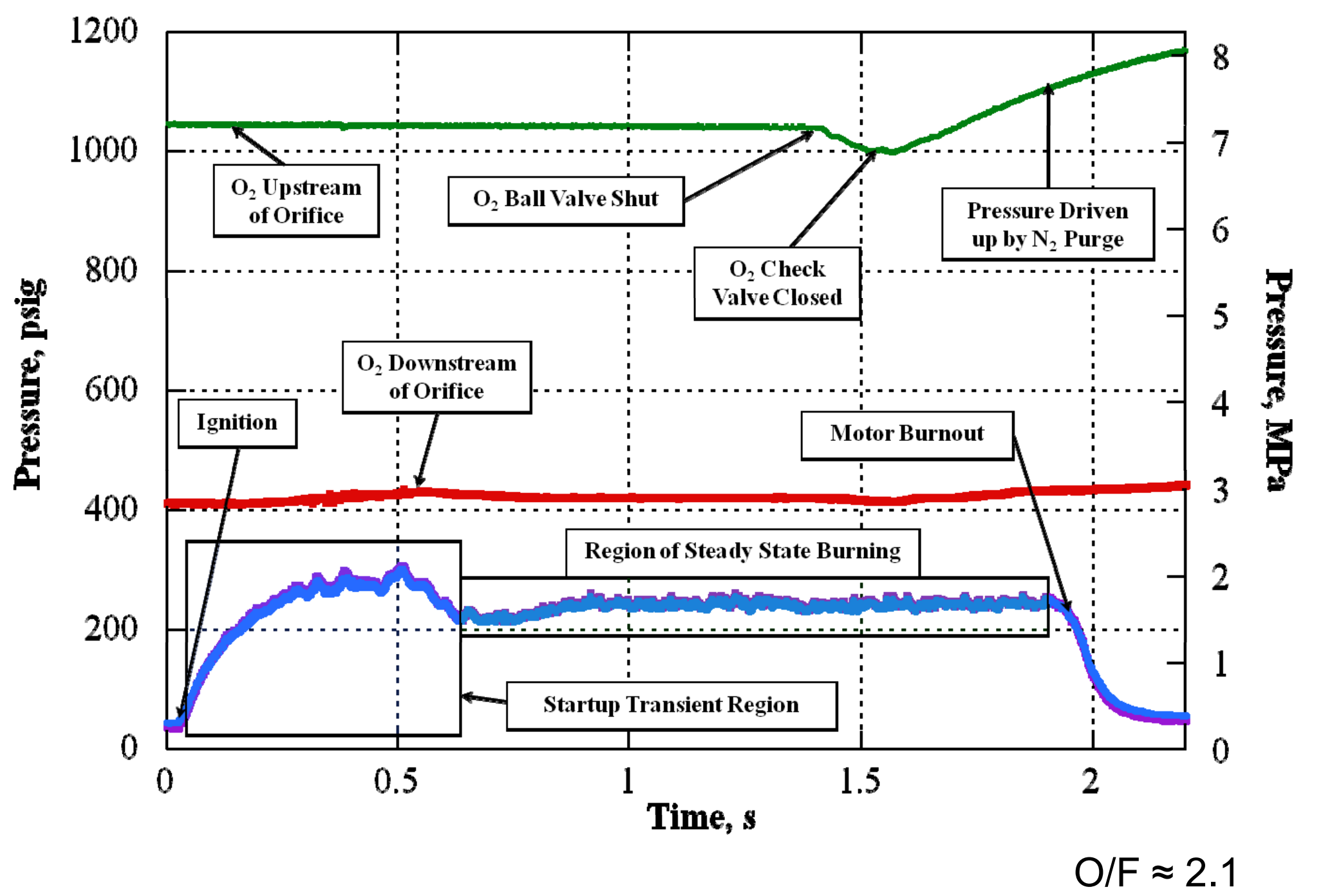




\section{PENNSTATE}

\section{Regression rates of various solid- \\ fuel formulations}

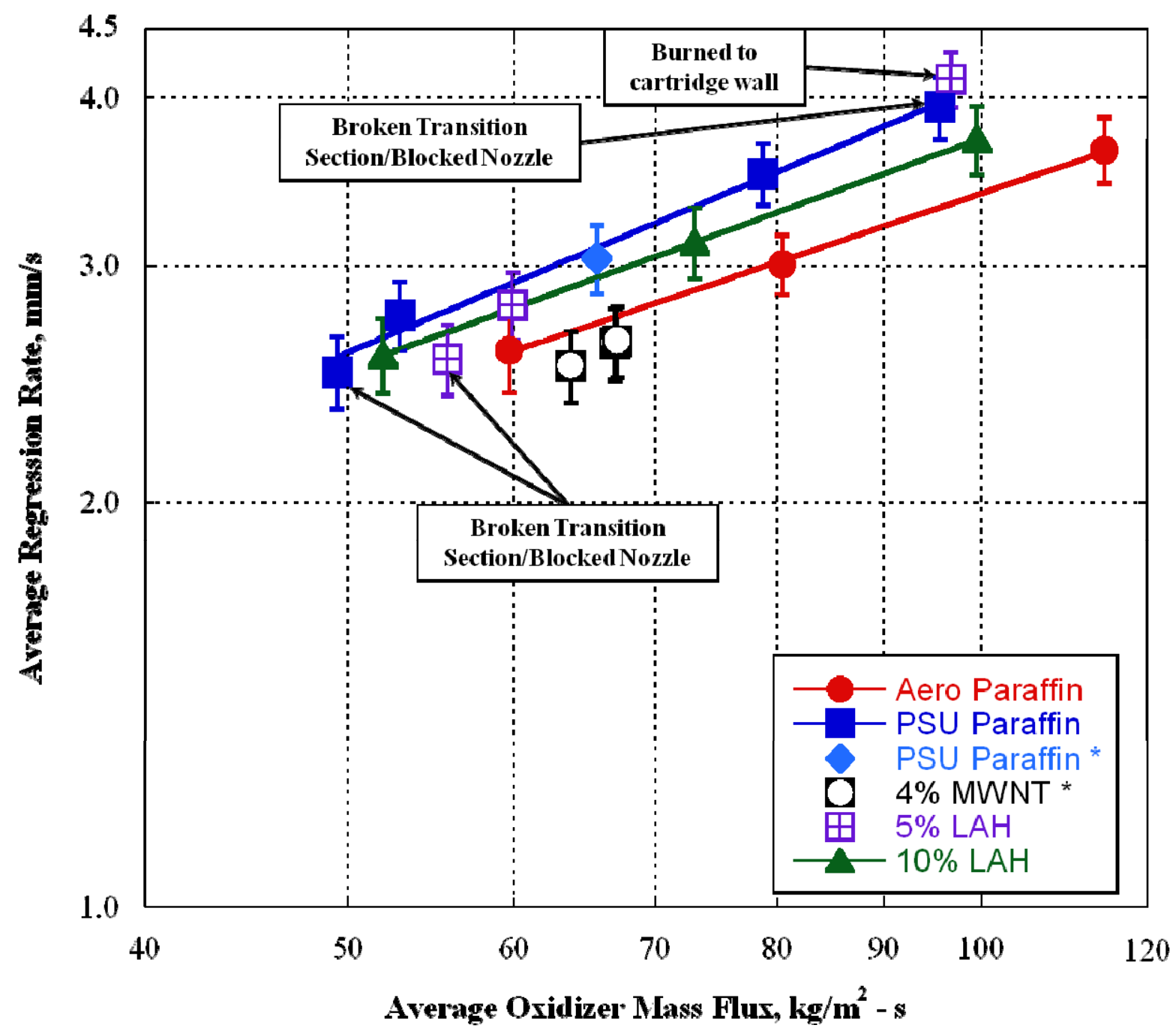




\section{PENNSTATE Mass burning rates of various solid- 4 AEROSPACE fuel formulations}

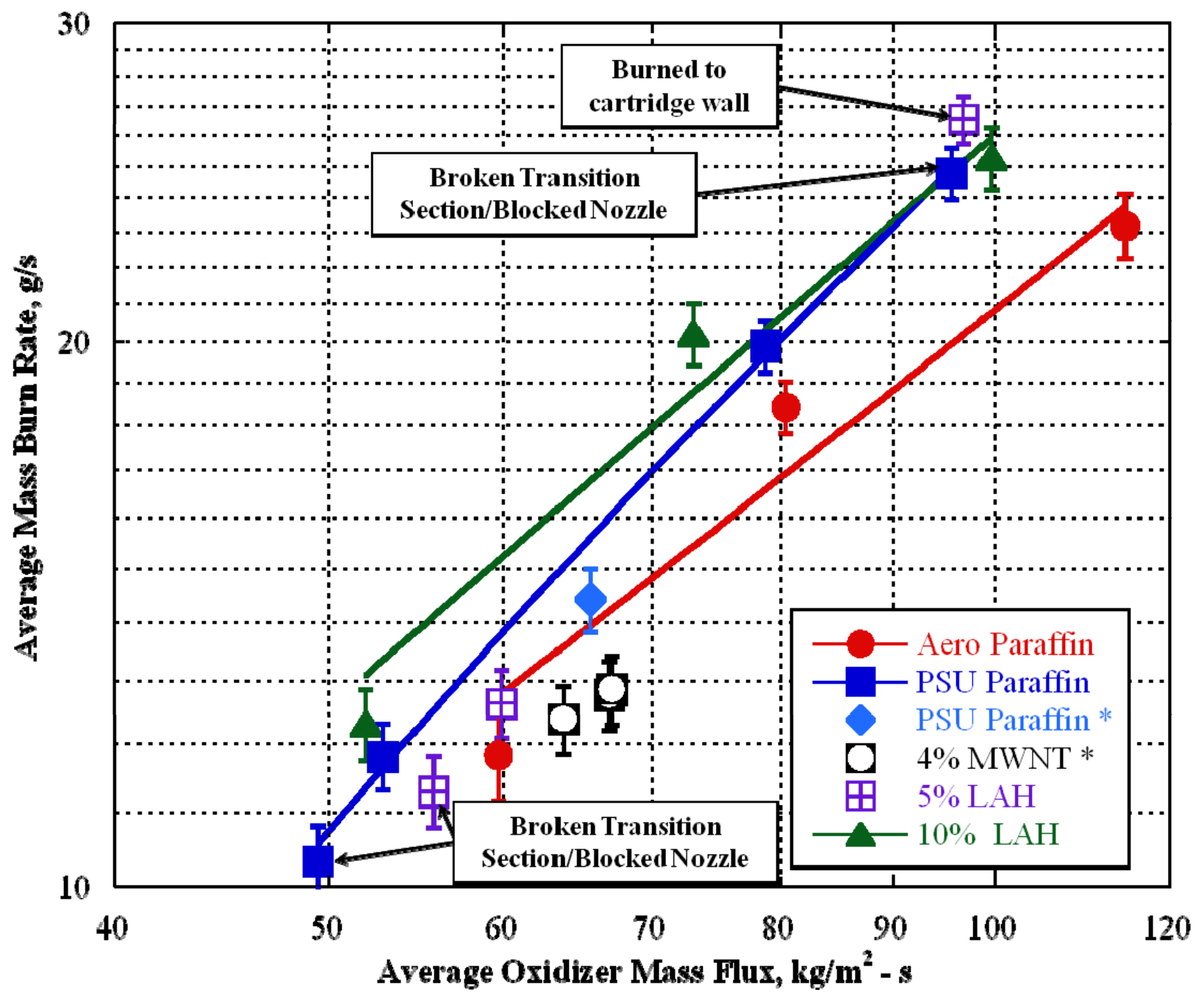




\section{Conclusions}

- Ball-milled $\mathrm{LiAlH}_{4}$ particle sizes were much smaller and fuel grains with $\mathrm{LiAlH}_{4}$ were very homogeneous

- Post firing grain geometry was also highly uniform

- $10 \% \mathrm{LiAlH}_{4}$ in paraffin showed $7-10 \%$ increase in regression rate over baseline paraffin (some increase due to lower density)

- $10 \% \mathrm{LiAlH}_{4}$ fuel grain also had higher mass burn rates

- Casts with MWNT showed good distribution, but MWNT were often bundled together

- Fuel grain with 4\% MWNT had slightly reduced regression rates, possibly due to increase in thermal conductivity

- RDX particles cast into paraffin wax using several casting methods were too large to produce fuel grain for hybrid testing

- Safe procedure developed, but more work with RDX/DMF/Paraffin solubility limits is required 


\section{Future work}

- Continue testing Paraffin/LiAlH ${ }_{4}$ fuel grains with higher $\mathrm{LiAlH}_{4}$ concentrations $(15-25 \%)$

- Cast new grains for use in the larger hybrid system at PSU's High Pressure Combustion Lab

- X-ray Translucent Center-perforated (XTC)

o Larger system means thicker web for longer burn

o X-ray diagnostics are conducive to accurate instantaneous fuel regression rate assessment

- Create Paraffin/MWNT samples for mechanical testing at University of Texas-Austin

- Generate fuel grains with carbon black in same percentage of MWNT to compare burn rates

- Carry out additional experiments on solubility limits of RDX/DMF/paraffin to achieve a uniform mixture with small RDX particles uniformly dispersed in the paraffin wax matrix 


\section{PENNSTATE}

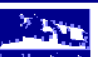

\section{Questions?}

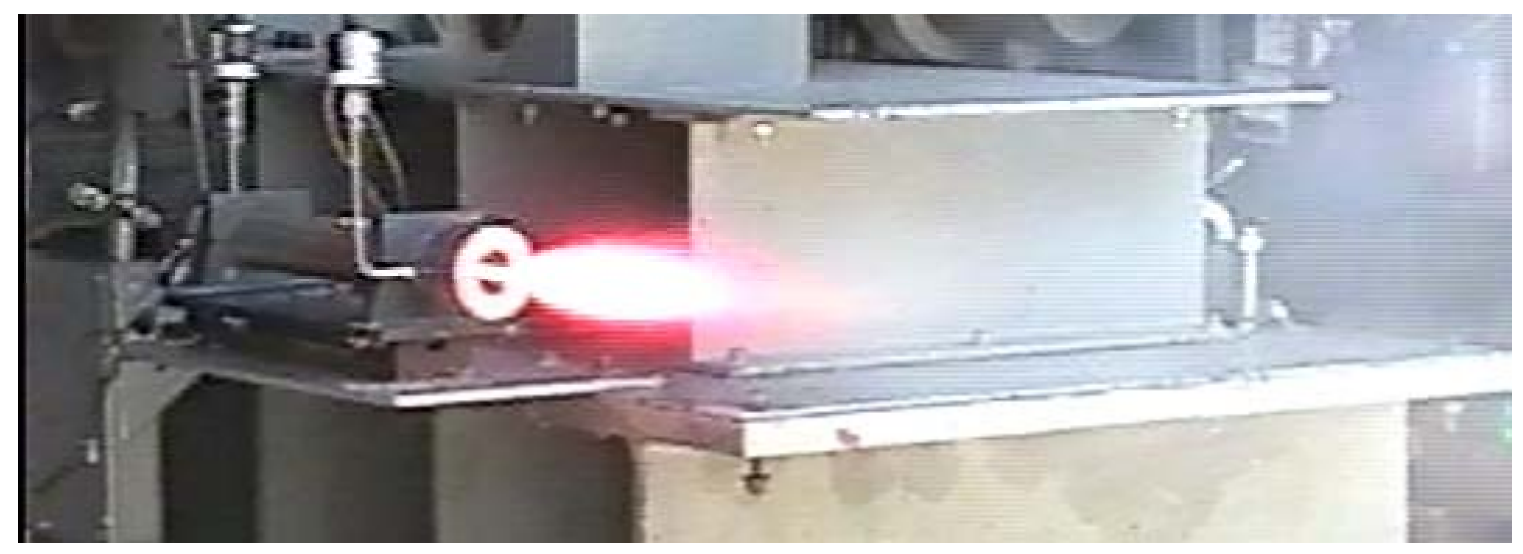

